\title{
Conditional Ablation of the Neural Cell Adhesion Molecule Reduces Precision of Spatial Learning, Long-Term Potentiation, and Depression in the CA1 Subfield of Mouse Hippocampus
}

\author{
Olena Bukalo, ${ }^{1 \star}$ Nikolas Fentrop, ${ }^{1 \star}$ Alan Y. W. Lee, ${ }^{1 \star}$ Benedikt Salmen, ${ }^{1 \star}$ Janice W. S. Law, ${ }^{1}$ Carsten T. Wotjak, ${ }^{1,2}$ \\ Michaela Schweizer, ${ }^{1}$ Alexander Dityatev, ${ }^{1}$ and Melitta Schachner ${ }^{1}$ \\ ${ }^{1}$ Zentrum fuer Molekulare Neurobiologie, Universitaet Hamburg, D-20246 Hamburg, Germany, and ${ }^{2}$ Max-Planck-Institut fuer Psychiatrie, D-80804 \\ Munich, Germany
}

\begin{abstract}
NCAM, a neural cell adhesion molecule of the immunoglobulin superfamily, is involved in neuronal migration and differentiation, axon outgrowth and fasciculation, and synaptic plasticity. To dissociate the functional roles of NCAM in the adult brain from developmental abnormalities, we generated a mutant in which the NCAM gene is inactivated by cre-recombinase under the control of the calciumcalmodulin-dependent kinase II promoter, resulting in reduction of NCAM expression predominantly in the hippocampus. This mutant $(\mathrm{NCAMff}+)$ did not show the overt morphological and behavioral abnormalities previously observed in constitutive NCAM-deficient $(\mathrm{NCAM}-/-)$ mice. However, similar to the NCAM $-/-$ mouse, a reduction in long-term potentiation (LTP) in the CA1 region of the hippocampus was revealed. Long-term depression was also abolished in NCAMff + mice. The deficit in LTP could be rescued by elevation of extracellular $\mathrm{Ca}^{2+}$ concentrations from 1.5 or 2.0 to $2.5 \mathrm{~mm}$, suggesting an involvement of NCAM in regulation of $\mathrm{Ca}^{2+}$-dependent signaling during LTP. Contrary to the NCAM $-/-$ mouse, LTP in the CA3 region was normal, consistent with normal mossy fiber lamination in NCAMff + as opposed to abnormal lamination in NCAM-1- mice. NCAMff + mutants did not show general deficits in short- and long-term memory in global landmark navigation in the water maze but were delayed in the acquisition of precise spatial orientation, a deficit that could be overcome by training. Thus, mice conditionally deficient in hippocampal NCAM expression in the adult share certain abnormalities characteristic of NCAM - / - mice, highlighting the role of NCAM in the regulation of synaptic plasticity in the CA1 region.
\end{abstract}

Key words: CA1; hippocampus; long-term depression; long-term potentiation; NCAM; water maze

\section{Introduction}

Recognition molecules are not only implicated in cell interactions during nervous system development, but they are also recognized as important mediators of synaptic plasticity in the adult (Schachner, 1997; Murase and Schuman, 1999; Benson et al., 2000). Among these molecules is the neural cell adhesion molecule (NCAM) (Lüthi et al., 1994; Muller et al., 1996, 2000; Staubli et al., 1998; Dityatev et al., 2000) and its associated $\alpha-2,8$ polysi-

\footnotetext{
Received July 11, 2003; revised Dec. 10, 2003; accepted Dec. 12, 2003.

This work was supported by the European community (QLKG-CT-1999-02187 to M.S.) and Deutsche Forschungsgemeinschaft (DI 702/1-1 to A.D.). A.Y.W.L. was a recipient of a research fellowship from the Alexander von Humboldt Foundation. We thank Michael Bösl for help in the transgenic mouse facility, Günther Schütz for the $\alpha$ CaMKIIcre transgenic mice, Francis Stewart for the plasmid pFLPe, Rita Gerardy-Schahn for the anti-PSA antibody, Gai Martin for the PGK-neomycin resistance cassette, and Andreas Nagy for embryonic stem cells. We also thank Constanze Rehbehn for technical assistance and Andreas Süllau for animal care.

*0.B., N.F., A.Y.W.L., and B.S. contributed equally to this work and are listed in alphabetical order.

Correspondence should be addressed to Melitta Schachner, Zentrum fuer Molekulare Neurobiologie, Universitaet Hamburg, Martinistrasse 52, D-20246 Hamburg, Germany. E-mail: melitta.schachner@zmnh.uni-hamburg.de.

A. Y. W. Lee's present address: Department of Physiology, National University of Singapore, 2 Medical Drive, Singapore 117597.

DOI:10.1523/JNEUROSCI.3298-03.2004

Copyright $\odot 2004$ Society for Neuroscience $\quad$ 0270-6474/04/241565-13\$15.00/0
}

alic acid (PSA) (Becker et al., 1996; Muller et al., 1996; Eckhardt et al., 2000). Antibodies against L1 or NCAM affect long-term potentiation (LTP), as studied in "acute" slices of the hippocampus (Lüthi et al., 1994), and influence passive avoidance learning in newly hatched chickens (Scholey et al., 1993, 1995; Tiunova et al., 1998) and adult rats (Doyle et al., 1992) as well as spatial learning of rats in the water maze (Arami et al., 1996). The percentage of synapses expressing the largest major isoform of NCAM, NCAM180, is increased in the dentate gyrus after long-term potentiation of the perforant pathway in the adult rat (Schuster et al., 1998). Also, NCAM changes its localization in the postsynaptic membrane after learning or modification of synaptic strength in the chick striatum (Skibo et al., 1998) and dentate gyrus of the adult rat (Fux et al., 2003).

NCAM was discovered as a transmembrane glycoprotein in the mouse (Cunningham et al., 1987) and is expressed by all neural cell types, subserving neuron-neuron and neuron-glia adhesion via homophilic and heterophilic interactions with other adhesion and extracellular matrix molecules. It is involved in signal transduction (for references, see Niethammer et al., 2002) and promotes neurite outgrowth and fasciculation (Rutishauser 
and Edelman, 1980; Fischer et al., 1986; Bixby et al., 1987; Doherty et al., 1990), neural crest cell migration (Bronner-Fraser et al., 1992), cerebellar neuron migration (Lindner et al., 1983), histogenesis of the retina (Buskirk et al., 1980), and muscle innervation (Landmesser et al., 1988).

Mice with a constitutive disruption of the NCAM gene show subtle morphological changes, such as reduction in the size of the olfactory bulbs, disturbed lamination of mossy fibers in the CA3 region of hippocampus, and impaired spatial learning and memory (Cremer et al., 1994, 1997; Stork et al., 1997; 1999). Longterm potentiation has been reported to be reduced in NCAMdeficient mice in CA1 (Muller et al., 1996, 2000; but see Holst et al., 1998) and CA3 (Cremer et al., 1998). Enzymatic removal of NCAM-associated PSA and genetic ablation of polysialyltransferase ST8SiaIV (required for polysialylation of NCAM in adult hippocampus) led to impairment of LTP and long-term depression (LTD) in CA1 (Becker et al., 1996; Muller et al., 1996; Eckhardt et al., 2000). NCAM-deficient mice also show increased aggressive behavior of males toward an unfamiliar male intruding into their home cage, correlating with an increase in activation of limbic system areas when compared with their wild-type control littermates (Stork et al., 1997). Furthermore, NCAMdeficient mice are more anxious and hypersensitive to serotonin 1A receptor agonists (Stork et al., 1999), most likely because of increased cell surface expression of the downstream signaling target of NCAM and serotonin 1A receptor, namely the Kir3.1/2 inwardly rectifying $\mathrm{K}^{+}$channels (Delling et al., 2002).

To dissociate the involvement of NCAM in synaptic plasticity and spatial memory in the adult brain from developmental effects, we used the Cre-loxP recombination system to generate a mutant in which the NCAM gene is ablated under the control of the $\alpha$ CaMKII promoter in hippocampal neurons postnatally.

\section{Materials and Methods}

Antibodies. Polyclonal antibodies against mouse NCAM have been described previously (Niethammer et al., 2002). For immunohistochemistry, affinity-purified polyclonal antibodies AB5032 against mouse NCAM were purchased from Chemicon (Temecula, CA). Monoclonal antibody against glyceraldehyde-3-phosphate dehydrogenase (GAPDH) was also purchased from Chemicon. Polyclonal antibodies directed against parvalbumin were from Sigma-Aldrich (Deisenhofen, Germany). Monoclonal antibody 735 against PSA was a kind gift from Dr. Rita Gerardy-Schahn (Medizinische Hochschule, Hannover). Antineurofilament polyclonal antibodies were from Serotec (Duesseldorf, Germany). Antibodies against glial fibrillary acidic protein (GFAP) were from Roche Products (Mannheim, Germany). Horseradish peroxidaseconjugated secondary antibodies against the respective primary antibodies were from Dianova (Hamburg, Germany), and biotinylated secondary antibodies were from Vector Laboratories (Burlingame, CA).

Construction of targeting vector. A PCR primer pair amplifying exon 1 of the mouse NCAM gene was used to screen a bacterial artificial chromosome (BAC) library prepared from genomic DNA of the 129SV strain of mouse (Research Genetics, Huntville, AL), resulting in the isolation of a BAC clone that covers the entire mouse NCAM gene. A $6 \mathrm{~kb} S p h \mathrm{I}-X h o \mathrm{I}$ fragment and a $5 \mathrm{~kb}$ SpeI fragment, harboring exons 1-4 and 5-6 of NCAM, respectively, were shuttled from this BAC clone to plasmid vectors to facilitate the construction of the gene-targeting vector. Target exon 5 was isolated and inserted into a pBS2loxP vector via XhoI and BsrDI sites so that it was flanked by two loxP sequences ("floxed") oriented in the same direction. The PGK (phosphoglycerate kinase)neomycin resistance (neo) cassette, flanked by a pair of frt sequences ("flrted") (a kind gift from Dr. Gail Martin, University of California, San Francisco, CA) was inserted upstream of exon 5 via the $X$ hoI site, resulting in a loxP-frt-neo-frt-exon5-loxP sandwich (see Fig. $1 A$ ). The $3.3 \mathrm{~kb}$ right homology arm of the targeting vector, which comprises exon 6 and intron 6 of the NCAM gene, was added at the BsrDI and XbaI sites. The construct was completed by a $6 \mathrm{~kb} K p n \mathrm{I}-\mathrm{XhoI}$ left arm that harbors exons 1-4.

Generation of NCAM-floxed and conditional NCAM-deficient mice. The targeting vector was linearized by NotI and electroporated into $1 \times$ $10^{7} \mathrm{R} 1$ embryonic stem (ES) cells (kindly provided by Dr. Andreas Nagy, Samuel Lunenfeld Research Institute, Toronto, Canada) (Nagy et al., $1993)$ at $3 \mu \mathrm{F}$ and $800 \mathrm{~V}$, followed by a second pulse of $500 \mu \mathrm{F}$ and $250 \mathrm{~V}$. After $7 \mathrm{~d}$ culture in selective medium containing $250 \mu \mathrm{g} / \mathrm{ml}$ of G418, surviving ES cell clones were isolated and expanded. To screen for the occurrence of a homologous recombination event, genomic DNA was isolated from individual ES cell clones and digested with PstI for Southern blot analysis using probe $\mathrm{A}$ as depicted in Figure $1 \mathrm{~A}$. Positive clones that carry the targeted alleles were then transiently transfected with a Flp-recombinase expression plasmid (pFLPe) (kindly provided by Dr. Francis Stewart, European Molecular Biology Laboratory, Heidelberg, Germany) (Buchholz et al., 1998) to remove the flrted neo cassette. After confirmation by Southern blot analysis, targeted ES cell clones heterozygous for the NCAM-floxed allele were injected into C57BL/6 blastocysts to generate chimeric mice. Male founders were crossed with C57BL/6 mice for three generations to ascertain germ line transmission of the targeted allele before being bred to homozygosity. To generate conditional NCAMdeficient mice, homozygous NCAM-floxed mice (NCAMff) were crossed with transgenic mice that express cre-recombinase under the control of the promoter for the $\alpha$ subunit of calcium-calmodulin-dependent protein kinase II ( $\alpha$ CaMKII) (line Camkcre4; kindly provided by Dr. Günther Schütz, German Cancer Research Center, Heidelberg, Germany) (Mantamadiotis et al., 2002). Although the progeny was heterozygous for the NCAM-floxed alleles, half of them carried the $\alpha$ CaMKII-cre transgene, and the rest were nontransgenic. Mice heterozygous for both the NCAM-floxed and the cretransgene were then crossed with homozygous NCAM-floxed mice to obtain conditional NCAM-deficient mice (NCAMff + ) and control littermates (NCAMff-). Unless otherwise stated, all experiments in the present study were performed on males.

PCR and Southern blot analyses. To isolate genomic DNA for PCR and Southern blot analyses, ES cells or mouse tail biopsies were subjected to proteinase $\mathrm{K}$ digestion, followed by phenol-chloroform extraction and ethanol precipitation. After preliminary screening with PCR amplification, genotypes were further confirmed by Southern blot analysis. Briefly, $20 \mu \mathrm{g}$ of purified genomic DNA was digested with appropriate restriction enzymes, fractionated on $0.7 \%$ agarose gels, and transferred onto nylon membrane (Hybond N+; Amersham, Freiburg, Germany). DNA was hybridized with a ${ }^{32} \mathrm{P}$-labeled probe at $65^{\circ} \mathrm{C}$ in hybridization buffer as depicted in Figure $1 A$. Nonspecific signals were removed by stringency washes in $2 \times, 1 \times$, and $0.1 \times$ SSC buffer. Hybridization signals were detected by $\mathrm{x}$-ray autoradiography.

Western blot analysis. Whole brain or subregions of brain (olfactory bulb, cerebral cortex, and hippocampus) at various ages were isolated from the mutants and control littermates for homogenization in ice-cold lysis buffer containing 20 mm Tris-Cl, pH 8.0, 1\% NP-40, $150 \mathrm{~mm} \mathrm{NaCl}$, $1 \mathrm{~mm}$ EDTA, $1 \mathrm{~mm}$ sodium orthovanadate, and protease inhibitor mixture (Roche Products). Crude protein extracts were obtained by clearing the lysates by centrifugation. Proteins were subjected to $8 \%$ SDS-PAGE and transferred onto nitrocellulose membrane (Protran; Schleicher \& Schuell, Dassel, Germany). After pretreatment in 2\% nonfat dry milk powder in $0.1 \%$ Tween 20 in PBS, pH 7.3, the membrane was incubated in the same solution containing NCAM polyclonal antibodies (1:5000). After washing in PBS, blots were incubated with horseradish peroxidaseconjugated anti-rabbit secondary antibody (1:5000). Immunoreactivity was detected by enhanced chemiluminescence (ECL kit; Amersham) on $\mathrm{x}$-ray film (Biomax; Kodak, Rochester, NY) according to the instructions of the manufacturer. Band intensity was quantified by densitometry.

Histological and immunohistochemical analyses. Mice were anesthetized and perfused transcardially with $4 \%$ paraformaldehyde in PBS. Brains were isolated and postfixed overnight in the same fixative. For Nissl staining, brains were paraffin-embedded and cut in $5 \mu \mathrm{m}$ sagittal sections. For immunohistochemical staining, 50-60 $\mu \mathrm{m}$ vibratome or frozen sections were prepared. Sections were incubated in $1 \%$ potassium borohydride in PBS for $10 \mathrm{~min}$, followed by an ascending series of ethanol. They were blocked with $10 \%$ horse serum and $0.1 \%$ bovine serum 
albumin (BSA) in PBS. Antibodies against parvalbumin (1:1000), neurofilament (1:1000), GFAP (1:1000), NCAM (AB5032; 1:500), and PSA (1:4000) in PBS containing $1 \%$ horse serum and $0.1 \%$ BSA were used. Immunoreactivities were detected using appropriate biotinylated secondary antibodies (1:1000; Vector Laboratories) and the ABC Elite Kit from Vector Laboratories. Nickel-enhanced $0.03 \%$ diaminobenzidine/ $0.015 \% \mathrm{H}_{2} \mathrm{O}_{2}$ was used as chromogene. The morphology of hippocampal mossy fibers was investigated by Timm's staining (Haug et al., 1971) with slight modification. Briefly, mice were perfused transcardially with sodium sulfide solution, followed by $4 \%$ paraformaldehyde in PBS. Ten micrometer coronal sections were cut and stained with a solution containing Arabic gum, hydroquinone, citric acid, and silver nitrite. All sections were examined with an Axiophot microscope (Zeiss, Goettingen, Germany).

Electrophysiological recordings. Two- to three-month-old NCAMff+ mice and their NCAMff - littermates of both sexes were used in all electrophysiological experiments. All recordings and measurements were done without knowing the genotype of the mice.

LTP and LTD in the CA1 region of the hippocampus. After halothane anesthesia, decapitation, and removal of the brain, transverse hippocampal sections were cut with a Leica VT $1000 \mathrm{M}$ vibratome (Leica, Nussloch, Germany) in ice-cold artificial CSF (ACSF) containing (in mM): 250 sucrose, $25 \mathrm{NaHCO}_{3}, 25$ glucose, $2.5 \mathrm{KCl}, 1.25 \mathrm{NaH}_{2} \mathrm{PO}_{4}, 2 \mathrm{CaCl}_{2}, 1.5$ $\mathrm{MgCl}_{2}, \mathrm{pH} 7.3$, adjusted with $\mathrm{NaOH}$. The slices were then kept for at least $2 \mathrm{hr}$ before the start of recordings at room temperature in carbogenbubbled ACSF, containing $125 \mathrm{~mm} \mathrm{NaCl}$ instead of $250 \mathrm{~mm}$ sucrose. Recordings were performed in the same solution, in a submerged chamber, at room temperature $\left(22-24^{\circ} \mathrm{C}\right)$, with varying concentrations of $\mathrm{Ca}^{2+}$ as indicated. Recordings of field EPSP (fEPSP) were performed in the stratum radiatum of the CAlb subfield with glass pipettes filled with ACSF and having a resistance of 1-2 M $\Omega$. Schaffer collaterals were stimulated with a bipolar electrode placed $\sim 300 \mu \mathrm{m}$ closer to the CA3 subfield than the recording electrode. Basal synaptic transmission was monitored at $0.05 \mathrm{~Hz}$. Following the previous study in NCAM-/- mice (Muller et al., 1996), theta-burst stimulation (TBS) was applied to induce LTP in CA1. The inter-TBS interval was $20 \mathrm{sec}$, and four TBSs were applied to induce LTP. TBS consisted of 10 bursts delivered at $5 \mathrm{~Hz}$. Each burst consisted of four pulses delivered at $100 \mathrm{~Hz}$. Duration of the pulses was $0.2 \mathrm{msec}$, and stimulation strength was set to provide baseline fEPSPs with an amplitude of $\sim 50 \%$ from the subthreshold maximum.

LTD was induced by two trains applied at $1 \mathrm{~Hz}$ for $10 \mathrm{~min}$ with a 10 min interval between them. Stimulation strength during baseline recordings and after induction of LTD was set to $30-40 \%$ of maximal fEPSPs. Stimulation strength was set to $60-70 \%$ when $1 \mathrm{~Hz}$ trains were delivered. This protocol has been shown to induce input-specific NMDA receptordependent LTD in adult rodents (Kerr and Abraham, 1995; Eckhardt et al., 2000).

LTP in the CA3 region of the hippocampus. The slices were prepared similarly as for recordings in the CA1 region, with some modifications as described previously (Eckhardt et al., 2000). To record mossy fiber responses in CA3 pyramidal cells, the stimulating electrode was placed close to the inner part of the granule cell layer, and the recording electrode was placed in the stratum lucidum. Recordings and stimulations were both performed with glass pipettes filled with ACSF and having a resistance of $2 \mathrm{M} \Omega$ with stimulation strength of $\sim 40 \mu \mathrm{A}$. The mossy fiber responses selected for recording were $40-60 \mu \mathrm{V}$, with a fast rise-time and decay of fEPSPs (total duration of fEPSP, $<10 \mathrm{msec}$; rise time $<3.5$ $\mathrm{msec})$, large paired-pulse facilitation $(>170 \%)$, and prominent frequency facilitation $(>200 \%)$. The selected responses had no hallmarks of polysynaptic activation, such as jagged decay phase with multiple peaks, or variable latencies of fEPSPs.

Following the previous study in NCAM-/- mice (Cremer et al., 1998), high-frequency stimulation (HFS) was applied to induce LTP in CA3. HFS consisted of one train of stimuli applied at $100 \mathrm{~Hz}$ during 0.4 or $1 \mathrm{sec}$. To evoke LTP exclusively in mossy fiber synapses, which are known to undergo LTP in an NMDA receptor-independent manner, the NMDA receptor antagonist AP-5 (50 $\mu \mathrm{M}$; Tocris Cookson, Bristol, UK) was applied 15 min before and during HFS. All recorded mossy fiber responses followed presynaptic stimulation of $100 \mathrm{~Hz}$ and showed no changes in the shape of responses after induction of LTP. To further confirm that the fEPSPs recorded were evoked by the stimulation of mossy fibers and not by the associational-commissural pathway, an agonist of type II metabotropic glutamate receptors (L-CCG1, $10 \mu \mathrm{M}$; Tocris Cookson), which is known to reduce synaptic transmission in CA3 mossy fiber synapses (Manzoni et al., 1995), was applied at the end of each experiment. Slices in which responses were reduced by at least $70 \%$ were selected for analysis. Statistical comparison of parameters measured in NCAMff + and NCAMff - mice was performed using the two-tailed $t$ test or two-way ANOVA. $p$ values $<0.05$ were accepted as providing significant differences between compared groups.

Water maze test. In the water maze test, mice learn to navigate to a submerged platform using visual cues for orientation. Mice were tested in a circular pool with a diameter of $150 \mathrm{~cm}, 30 \mathrm{~cm}$ water depth, and a 20 $\mathrm{cm}$ high white wall above the water level. Water was made opaque with nontoxic white paint and maintained at $22 \pm 2^{\circ} \mathrm{C}$. During the training period, the circular target platform ( 20 or $15 \mathrm{~cm}$ in diameter) was submerged $\sim 10 \mathrm{~mm}$ under the water surface at a fixed position (shortest distance of platform center to the wall of the pool, $33 \mathrm{~cm}$ ). The walls, doors, and ceiling of the test room were white (painted or covered with cloth) to minimize uncontrolled visual landmarks. Prominent extramaze visual cues for orientation (global landmarks) were provided by three posters with high-contrast black and white patterns and four white posters with black line drawings (50-60 $\mathrm{cm}$ rectangle). They were placed at a horizontal distance of $100-120 \mathrm{~cm}$ to the pool and a vertical elevation of $120-150 \mathrm{~cm}$ over the water surface. One poster with black line drawings was positioned at the ceiling $150 \mathrm{~cm}$ above the water surface. Light intensity at the water surface was 35-36 lux, and visual landmarks were directly illuminated at 200-500 lux. In an attempt to eliminate possible intermaze cues, the flexible wall of the pool was turned before each new trial in a pseudorandom manner. All sessions were videotaped and analyzed by means of a video tracking system (five samples per second; Ethovison V1.96; Noldus, Wageningen, The Netherlands). Both video and computer equipment (except for the camera) were localized in the pretest room to minimize interference with the tests.

Three- to four-month-old NCAMff + mice and NCAMff- littermates ( $n=14$ of each) were housed singly under an inverse $12 \mathrm{hr}$ light/dark cycle (lights off at 7:00 A.M.) for at least 2 weeks before starting the experiment. All animals were transported from the vivarium to the adjacent pretest room $\sim 20$ min before experiments. Experiments were performed between 9:00 A.M. and 5:00 P.M. (i.e., during the activity phase of the animals). At the start of the test, mice were individually transferred to the adjacent test room in an opaque plastic container and placed into water with their heads facing toward the wall. Mice started from six fixed starting positions in pseudorandom order (average distance to the platform was similar for all subsequent trial pairs). A trial was terminated as soon as the mouse climbed onto the platform. If animals failed to find the platform within $120 \mathrm{sec}$, the experimenter indicated the position of the platform by placing a rod with a metal grid onto it. Mice were allowed to rest on the platform for at least $10 \mathrm{sec}$ before being returned to their home cages in the adjacent laboratory by means of a metal grid. Mice were kept warm and dry under a red light heating lamp ( $\sim 250$ lux $)$ after each session.

Mice were trained to find the submerged platform in the NE quadrant over a period of $5 \mathrm{~d}$ (days $1-4$, six learning trials per day; day 5 , four learning trials at an intertrial interval of 60-120 min). Training trials at day 5 were followed by a probe trial ( $120 \mathrm{sec}$ of free swim with no platform) and two additional training trials with the platform in NE. Another probe trial was performed $64 \mathrm{hr}$ later to evaluate long-term spatial memory. At training days 1 and 2, mice had to navigate to the platform with a diameter of $20 \mathrm{~cm}$. The larger platform was used to facilitate acquisition of the task (Gerlai et al., 2002). From training day 3 onward, the platform diameter was reduced to $15 \mathrm{~cm}$ to render the task more difficult and to assess the accuracy of spatial navigation. At day 3, data were analyzed off-line with both the actual $(15 \mathrm{~cm})$ and the former, now virtual, platform size $(20 \mathrm{~cm})$. Learning performance of the mice was measured by the time taken to reach the real (or virtual) platform (escape latency), the length of the swim path and the swim speed. The search strategy was evaluated by measuring the mean distance to the platform position, 
which was calculated by the Ethovision software for each trial and animal. We also calculated the mean distances to three virtual platforms, which were defined in the computer in the three other quadrants with reference to the platform position in the NE quadrant (see Fig. $8 \mathrm{~B}$ ). For the probe trials, we also measured the relative time spent in each of the four quadrants, the relative length of the swim path per quadrant, and the number of visits of the former and the three virtual platform positions. Data (mean \pm SEM) were analyzed trial- or day-wise as indicated. Statistical significance was accepted if $p<0.05$.

\section{Results}

Generation of conditional

NCAM-deficient mice

To restrict ablation of the NCAM gene to brain subregions after early development, we generated a conditional mutant using the bipartite cre-loxP recombination system ( $\mathrm{Gu}$ et al., 1994). Two genetically modified mice were involved: (1) a chimeric mouse in which a pair of the loxP sequence was engineered into the NCAM gene to flank the target exon (NCAMfloxed mouse), and (2) a transgenic mouse that expresses the cre-recombinase under the control of the $\alpha$ CaMKII promoter (CaMKcre mouse). To generate the NCAM-floxed mouse, exon 5 was chosen as the target exon because its removal would lead to a shift in reading frame and termination of translation. The genetargeting construct was built by inserting a flrted (flanked by frt site) neomycinresistance cassette at a position upstream of exon 5, which was flanked by a pair of loxP (floxed) sequences (Fig. 1A). To screen for ES cells that had undergone homologous recombination with the targeting vector, genomic DNA isolated from clones that survived G418 selection was digested with PstI and subjected to Southern blot analysis using probe A (Fig. 1 A). A 5.1 $\mathrm{kb}$ band was detected for the wild-type NCAM allele, whereas a $4 \mathrm{~kb}$ band was observed for the targeted allele resulting from the introduction of an extra PstI site in the targeting construct (Fig. $1 B$ ). Targeted ES cells were then transiently transfected with a Flp-recombinase expression vector (Buchholz et al., 1998) to remove the flrted neo cassette, which may have undesirable effects on endogenous NCAM expression even before cremediated excision (Jacks et al., 1994; Minichiello et al., 1999). Clones that were free of the neo cassette were distinguished by a $1.7 \mathrm{~kb}$ band in Southern blot hybridization of HindIII-digested genomic DNA using exon 5 as a probe (Fig. 1C), with "contaminating" wild-type ES cells giving rise to a single $5.1 \mathrm{~kb}$ band. Two independent ES cell clones were selected for expansion and microinjected into mouse blastocysts to generate chimeric mice. Germ line transmission of the NCAM-floxed allele was confirmed by Southern blot analysis of PstI-digested genomic DNA isolated from the resulting progenies (data not shown). To ascer-
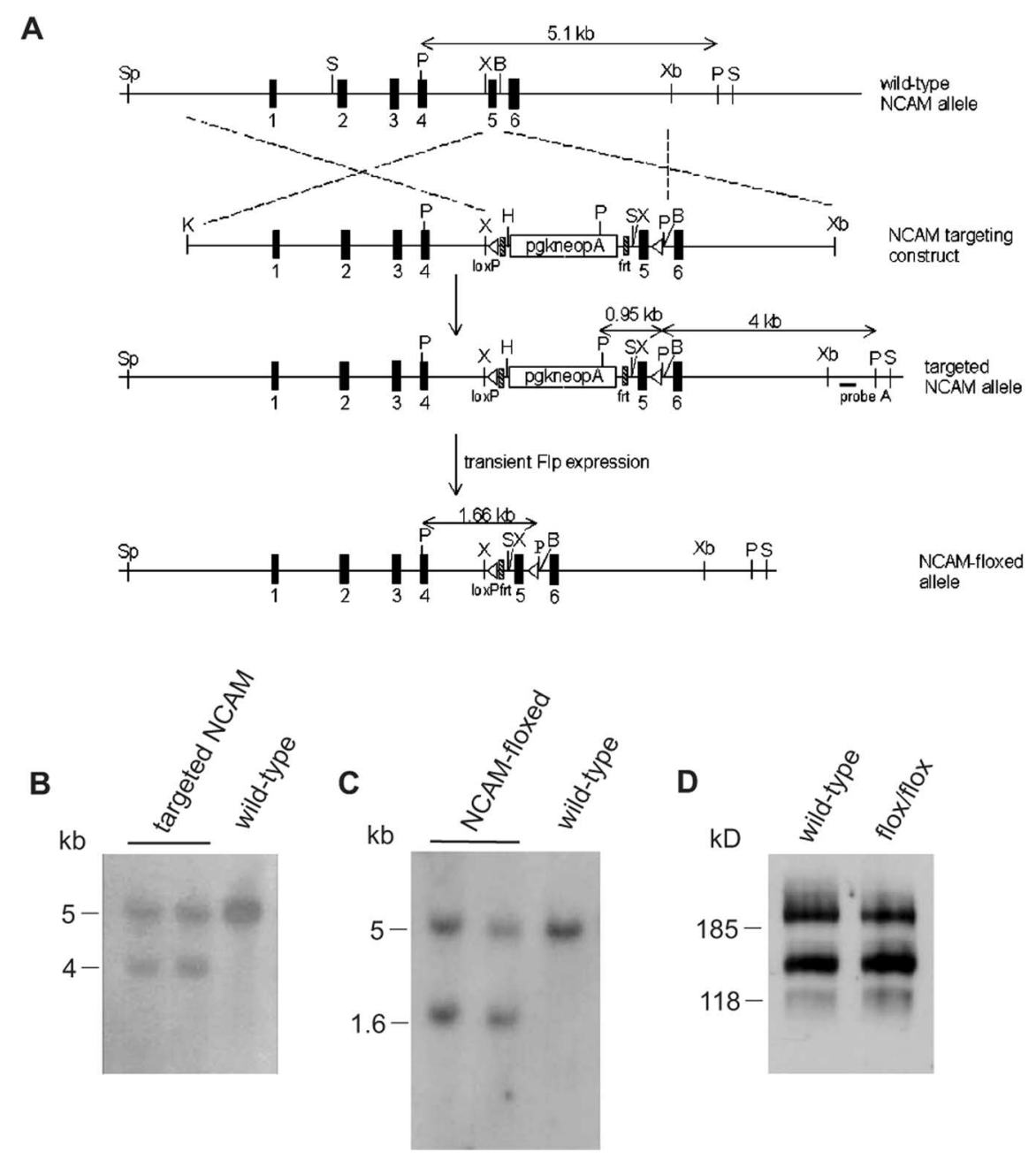

Figure 1. Generation of NCAM-floxed (NCAMff+) mice. A, Schematic representation of the organization of the wild-type mouse NCAM gene, targeting vector, targeted NCAM gene locus, and neomycin-resistance (neo) cassette-free loxP-flanked NCAM floxed exon 5 . The neo cassette was subsequently removed by transient expression of Flp-recombinase in the targeted clones. $B$, BsrDI; H, HindIII; K, Kpnl; P, Pstl; S, Sacl; Sp, Sphl; X, Xhol; Xb, Xbal. B, Successfully targeted ES cell clones (targeted NCAM) were resulting from the introduction of an additional Pstl site in the targeting construct, whereas the wild-type allele produced a $5.1 \mathrm{~kb}$ fragment. C, Removal of the neo cassette in targeted ES cell clones (NCAM-floxed) was verified by Southern blot analysis of Pst digested genomic DNA. Targeted clones were identified by hybridization with an exon 5 probe yielding a $1.7 \mathrm{~kb}$ fragment, indicating excision of the neo cassette, whereas wild-type clones were identified by a $5.1 \mathrm{~kb}$ band. D, Western blot analysis of NCAM protein in the brain of adult mice homozygous for the NCAM-floxed allele (flox/flox; NCAMff-) and their wild-type littermates. Forty micrograms of crude lysates from total brains of the two genotypes were loaded onto each lane.

tain normal expression of NCAM in the presence of frt and loxP sequences, Western blot analysis was performed on proteins isolated from the brains of mice homozygous for the NCAM-floxed allele and their wild-type littermates. Both the isoform profile and expression level of NCAM were indistinguishable in these two genotypes (Fig. $1 D$ ), as shown by the similar intensities of the three major NCAM immunoreactive bands.

\section{Generation of mice lacking NCAM in the hippocampus}

To inactivate NCAM function in the postnatal brain, floxed NCAM mice were bred to a transgenic line that expresses crerecombinase under the control of the $\alpha$ CaMKII promoter. This promoter has previously been demonstrated to drive heterologous gene expression in postnatal hippocampus and forebrain (Mayford et al., 1995; Mantamadiotis et al., 2002), although subregion differences may occur among transgenic lines (Tsien et al., 
A

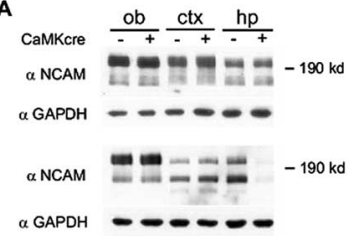

B

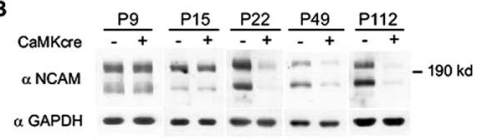

C

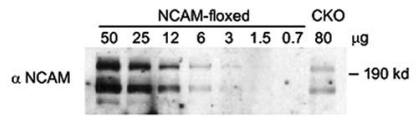

Figure 2. Expression level of NCAM protein in brain subregions of NCAMff - and NCAMff + mice. A, Western blot analyses were performed on tissue homogenates from olfactory bulb (ob), cerebral cortex (ctx), and hippocampus (hp) of mice homozygous for the NCAM-floxed allele and heterozygous for the $\alpha$ CaMKII-cre transgene (NCAMff + ) and mice homozygous for the NCAM-floxed allele but negative for the $\alpha$ CaMKII-cre transgene (NCAMff - ). Thirty micrograms of crude tissue lysates were loaded onto each lane. NCAM expression levels, as detected by polyclonal NCAM antibodies, were not different between the two genotypes in these brain regions at $P 9$ (top panel), whereas at $P 112$ (bottom panel), NCAM levels were decreased in the hippocampus of NCAMff + mice. Protein loadings were controlled by GAPDH immunoreactivity. B, Western blot analysis of NCAM expression in the hippocampus of NCAMff- and NCAMff + mice at P9, P15, P22, P49, and P112. Thirty micrograms of crude tissue lysates were loaded onto each lane. C, Eighty micrograms of crude tissue lysates of hippocampus isolated from 49-d-old NCAMff + mutants (CKO) and a range of $0.7-50 \mu \mathrm{g}$ of protein from hippocampus of 49-d-old NCAMff- controls (NCAM-floxed) were subjected to Western blot analysis using NCAM antibodies to estimate the efficiency of CaMKII-cre-mediated inactivation of NCAM expression in the hippocampus. All samples were pooled from two to three animals.

1996). The resulting progenies that are homozygous for the NCAM-floxed allele and heterozygous for the CaMKII-cre transgene (NCAMff + ) were compared with their nontransgenic NCAM-floxed littermates (NCAMff-) for the pattern and level of NCAM expression in the brain. Specificity and efficiency of cre-mediated NCAM disruption were assayed by Western blot analysis of homogenates isolated from several brain regions of NCAMff + and NCAMff- mice using polyclonal NCAM antibodies. At postnatal day (P9) and P15, there was no difference between the genotypes in levels of expression of the major NCAM isoforms (NCAM180, NCAM140, and NCAM120) in olfactory bulb, cerebral cortex, and hippocampus of both genotypes (Fig. $2 A$, top panel, day 9). Normal NCAM expression in NCAMff+ mice was also observed in the olfactory bulb and cerebral cortex at P112 (Fig. 2A, bottom panel). At P22, however, a significant reduction of NCAM expression was observed in the hippocampus of NCAMff + mutants but not in the NCAMff- floxed littermates (Fig. $2 \mathrm{~B}$ ). A further reduction of NCAM protein expression was found in the hippocampus of NCAMff + mice at P49 and P112 (Fig. $2 A$, bottom panel, $B$ ).

To estimate the residual amount of NCAM and the efficiency of NCAM ablation by cre-recombinase in the hippocampus, we compared the intensity of NCAM signals in Western blot analyses of proteins isolated from the NCAMff + mutants and the NCAM-floxed littermates at P49. A range of $0.7-50 \mu \mathrm{g}$ of protein extracts isolated from the hippocampus of NCAMff- control littermates and $80 \mu \mathrm{g}$ of hippocampal proteins from NCAMff + mutants were subjected to Western blot analyses using polyclonal NCAM antibodies (Fig. 2C). Densitometric analysis showed that the intensity of NCAM immunoreactivity of $80 \mu \mathrm{g}$ of NCAMff + hippocampus was equivalent to that of $7 \mu \mathrm{g}$ of the NCAMff- littermate. The residual NCAM protein in the hippocampus of NCAMff + mice was $\sim 10 \%$ of the level of endogenous NCAM expression as estimated by densitometric analysis.

The expression pattern of NCAM and its associated PSA in NCAMff + mice was also examined immunohistochemically at P63-P70 using constitutive NCAM-deficient mice (NCAM-/-) (Cremer et al., 1994) as a control for the specificity of immunostainings. (Note that this method does not allow precise quantitative estimates of NCAM expression). Frontal sections of the whole brain stained with an affinity-purified polyclonal antibody directed against all NCAM isoforms showed a distinct reduction in NCAM immunoreactivity in the hippocampus, less in the cerebral cortex and not in deeper brain structures (Fig. $3 A_{1}-C_{1}$ ), including the thalamus and hypothalamus. Similarly, a clear reduction in the amount of PSA in the hippocampus, but not in other brain areas, was seen using monoclonal antibodies against PSA (Fig. $3 D_{1}-F_{1}$ ). The immunostaining patterns were indistinguishable in wild-type (data not shown) and NCAMff- mice. In the hippocampus of NCAMff + mice, NCAM (Fig. $3 B_{2}$ ) or PSA (Fig. $3 E_{2}$ ) immunoreactivity was not associated with pyramidal or granule cells. A striking loss of NCAM and PSA immunoreactivity was observed in the mossy fiber projections and in the molecular layer of the dentate gyrus (Fig. $3 A_{2}-F_{2}$ ). NCAM immunoreactivity was detectable in the inner part of the granule cell layer of the dentate gyrus, where immature neurons are located, in which the CaMKII promoter is most likely not active, and in the hilus, alveus, and stratum lacunosum-moleculare, which receive inputs from striatal and cortical neurons, evidently expressing NCAM and PSA (Fig. $3 A_{2}-F_{2}$ ). These data suggest that a major portion of residual NCAM expression in the hippocampus is derived from axons projecting to the hippocampus. Furthermore, because NCAM is expressed not only by neurons (Persohn et al., 1989; Prieto et al., 1989) but also by glia (Keilhauer et al., 1985; Noble et al., 1985), and because the $\alpha$ CaMKII promoter has not been reported to be active in glia, NCAM expression in the hippocampus may also be attributable to the presence of astrocytes and, less so, oligodendrocytes.

\section{Morphological analyses}

Although NCAM is expressed during ontogenetic development and remains expressed in all neural cell types in the adult, mice constitutively deficient in NCAM expression (NCAM-/-) show unexpectedly mild phenotypes, which include a reduction in brain weight and size of the olfactory bulb (Cremer et al., 1994) as well as an altered cytoarchitecture of the hippocampus (Tomasiewicz et al., 1993; Cremer et al., 1997). These abnormalities could contribute to the behavioral phenotypes reported for these mutants (Cremer et al., 1994; Stork et al., 1997, 1999; Wood et al., 1998). Having confirmed the inactivation of NCAM in the postnatal hippocampus, we examined NCAMff + mice for morphological abnormalities. In contrast to NCAM - / - mice, the overall size of the brain and the olfactory bulb of NCAMff + mice were indistinguishable from the NCAMff - and wild-type mice (data not shown). Nissl staining revealed no abnormalities in size and overall structure of the hippocampus of adult NCAMff + mutants at all stages examined (from P22 to P126) (for P112, see Fig. $4 A, F)$. In view of the findings that hippocampal mossy fibers are disorganized in the pyramidal cell layer of NCAM $-/-$ mice (Cremer et al., 1997, 1998), we asked whether a similar phenotype would be observed in NCAMff + mice. Timm's staining of the mossy fiber system in NCAMff + and NCAMff - mice revealed a similarly strong and homogenous signal extending from the hilus to the CA3-CA2 border in both genotypes (Fig. $4 B, G$ ). Neuro- 
filament immunostaining in NCAMff+ mice did not show the characteristic dispersed and bilayered pyramidal cell layer in the CA3 subfield of NCAM - / - mice (Cremer et al., 1997) (Fig. 4C,H). Numbers and morphology of parvalbumin-positive interneurons, which do not express CaMKII, were normal in the hippocampus of NCAMff+ mutants (Fig. 4D,I). Similarly, the pattern of GFAP immunoreactivity of astrocytes was normal in the mutants (Fig. $4 E, J)$. Thus, no major abnormalities were found in NCAMff + mice by histological analysis at the light microscopic level.

\section{Electrophysiological recordings}

In view of previous studies of NCAM - / mice showing a deficit in LTP in the CA1 region of the hippocampus (Muller et al., 1996, 2000), we compared TBS-induced LTP in CA1 between NCAMff+ and NCAMff - littermates. Following our previous studies in acute hippocampal slices (Eckhardt et al., 2000), we used the same $(2.0 \mathrm{~mm})$ and more physiological [1.5 mM; see references in Stringer and Lothman (1988)] extracellular $\mathrm{Ca}^{2+}$ concentrations during recordings. Multiple TBS trains were applied to induce short-term potentiation (STP) and LTP in synapses formed by the Schaffer collaterals in the CA1 region. The mean level of STP measured as maximal potentiation above the baseline during 1 min after TBS in NCAMff- mice was $113.3 \pm 10.7 \%$ at $1.5 \mathrm{mM} \mathrm{Ca}^{2+}$ and $104.2 \pm 8.3 \%$ at $2.0 \mathrm{mM} \mathrm{Ca}^{2+}$, whereas the levels of LTP seen 50-60 min after TBS were $44.0 \pm 5.5$ and $29.0 \pm 4.3 \%$ (above the baseline), respectively (Fig. $5 A_{1}, A_{2}$ ). The level of STP in NCAMff + mice was normal at both $1.5 \mathrm{mM} \mathrm{Ca}^{2+}(97.6 \pm$ $11.9 \%)$ and $2.0 \mathrm{mM} \mathrm{Ca}^{2+}(85.6 \pm 4.6 \%)$ compared with NCAMff - mice $(p>0.1$; $t$ test). Also, the fEPSPs elicited by TBS were similar in both genotypes (Fig. $\left.5 B_{1}, B_{2}\right)$. However, the levels of LTP recorded 50-60 min after TBS were significantly reduced in NCAMff + mice to $21.1 \pm 5.8 \%$ at $2.0 \mathrm{mM} \mathrm{Ca}^{2+}$ and $15.8 \pm$ $3.2 \%$ at $1.5 \mathrm{mM} \mathrm{Ca}^{2+}(p<0.05)$ (Fig. $\left.5 A_{1}, A_{2}, E\right)$.

Although several groups, including ours, found an impaired LTP in the CA1 region of NCAM- or PSA-NCAM-deficient mice, one study did not detect differences in the magnitude of LTP between NCAM - / - mice and their wild-type littermates (Holst et al., 1998). In this study, $2.5 \mathrm{mM} \mathrm{Ca}^{2+}$ was present in the bath solution. When we used a $\mathrm{Ca}^{2+}$ concentration of $2.5 \mathrm{mM}$, the levels of STP were significantly reduced in both NCAMff + and NCAMff - mice compared with those at 1.5 and $2.0 \mathrm{mM} \mathrm{Ca}^{2+}(p<$
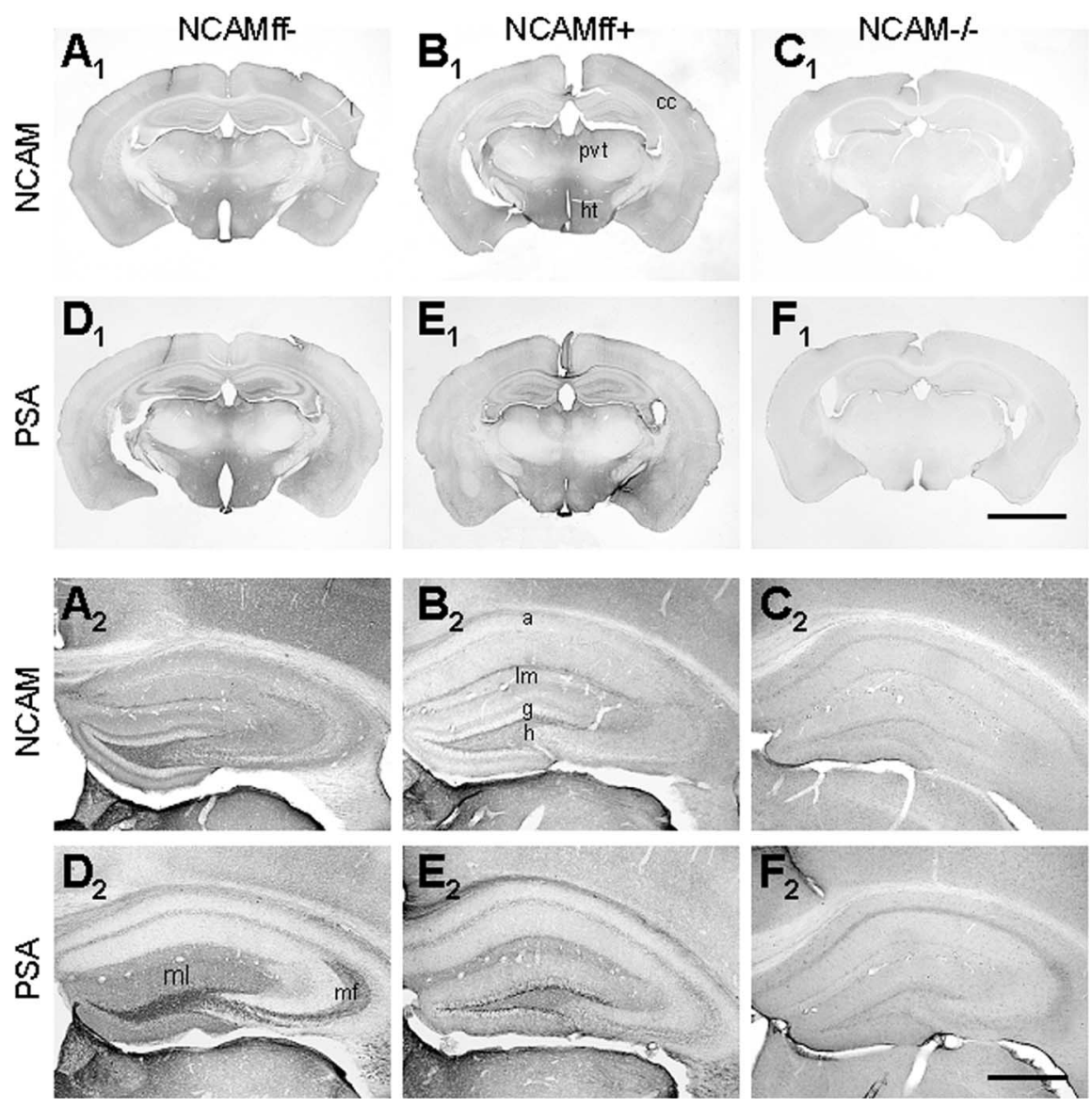

Figure 3. NCAM and PSA immunoreactivity in the brains of NCAMff - and NCAMff + mice. $A_{1}-F_{1}$, Frontal brain sections of 63 to 70-d-old NCAMff- $\left(A_{1}, D_{1}\right)$, NCAMff $+\left(B_{1}, E_{1}\right)$, and constitutive NCAM-deficient mice (NCAM-I-; $\left.C_{1}, F_{1}\right)$ stained with polyclonal antibodies against all NCAM isoforms and with a monoclonal antibody to PSA. Note the normal expression pattern of NCAM and PSA in the cerebral cortex (cc), paraventricular thalamic nucleus (pvt), and hypothalamus (ht) in NCAMff- and NCAMff + mice compared with constitutive NCAM-deficient (NCAM - / -) mice. Scale bar, $2.5 \mathrm{~mm} . A_{2}-F_{2}$, NCAM and PSA immunoreactivity in the hippocampi of NCAMff-, $\mathrm{NCAMff}+$, and NCAM- - - mice, corresponding to images shown in panels $A_{1}-F_{1}$. Loss of NCAM and PSA immunoreactivity in the molecular layer of the dentate gyrus $(\mathrm{ml})$ and the mossy fibers $(\mathrm{mf})$ is particularly obvious. Residual levels of NCAM and PSA remain in the inner granule cell layer $(\mathrm{g})$, hilus $(\mathrm{h})$, stratum lacunosummoleculare (Im), and alveus (a). Scale bar, $0.5 \mathrm{~mm}$.
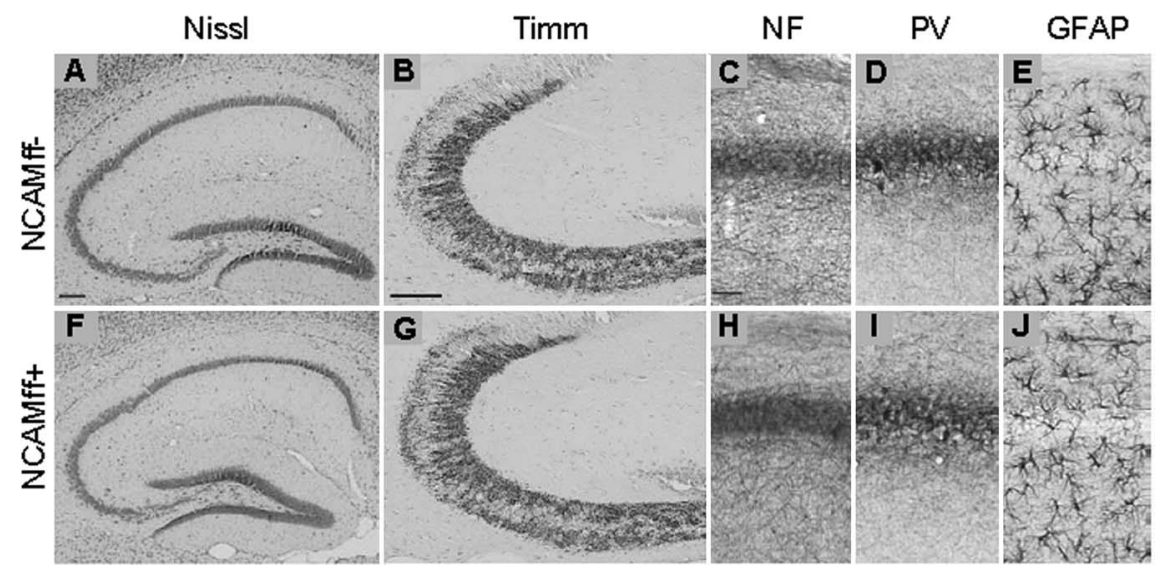

Figure 4. Histological characterization of hippocampal structures in NCAMff - and NCAMff + mice. A, F, Nissl staining of hippocampi from NCAMff- $(A)$ and NCAMff + mice ( $F) . B$, G, Timm's staining of mossy fibers in NCAMff - $(B)$ and NCAMffcontrol mice $(G) . C-E, H-J$, Immunostainings of the CA1 region from NCAMff- and NCAMff + mice for neurofilament $(\mathrm{NF} ; C, H)$, parvalbumin (PV; $D, I)$, and GFAP $(E, J)$. Sagittal sections of 112-d-old mice were used for these analyses. No significant differences between genotypes were obvious. Scale bars: $A, B, F, G, 100 \mu \mathrm{m} ;(-E, H-J, 50 \mu \mathrm{m}$. 


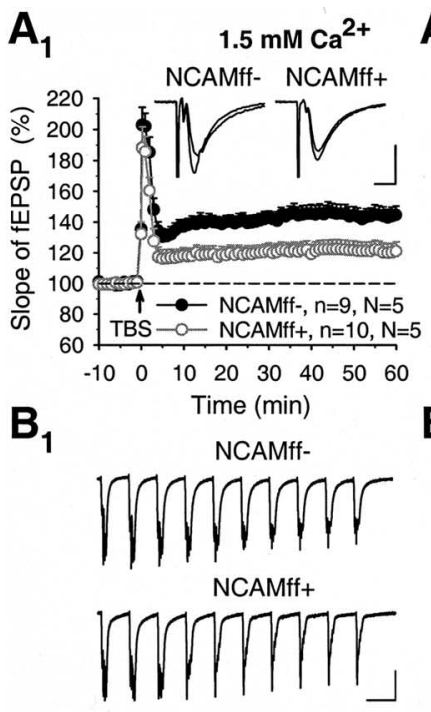

C

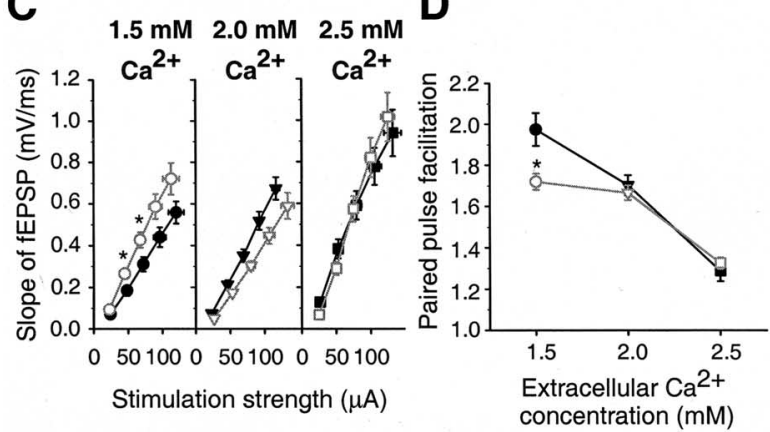

Figure 5. LTP is reduced in NCAMff + mice to 1.5 and $2.0 \mathrm{~mm}$ but not at $2.5 \mathrm{~mm}$ extracellular $\mathrm{Ca}^{2+}$ concentration. $A_{1}-A_{3}$, TBS of Schaffer collaterals at $1.5 \mathrm{~mm}\left(A_{1}\right), 2.0 \mathrm{~mm}\left(A_{2}\right)$, or $2.5 \mathrm{~mm}\left(A_{3}\right)$ extracellular $\mathrm{Ca}^{2+}$ concentrations increases slopes of fEPSPs in the CA1 region of slices from NCAMff - mice. In slices from NCAMff + mice, potentiation is lower than in NCAMff - mice at 1.5 and 2.0 mm extracellular $\mathrm{Ca}^{2+}$ concentration. The mean slope offEPSPs recorded $0-10$ min before TBS was taken as $100 \%$; arrows indicate delivery of TBS. In all panels, data represent mean \pm SEM, $n$ provides the number of tested slices, and $N$ provides the number of tested mice. The symbols and numbers shown in $A_{1}-A_{3}$ are also valid for $C-E$. Insets show averages of $30 \mathrm{fEPSPS}$ recorded $10 \mathrm{~min}$ before and $50-60 \mathrm{~min}$ after TBS. Calibration: $\left(A_{1}-A_{3}\right), 10$ msec and $0.5 \mathrm{mV} . B_{1}-B_{3}$, fEPSPs evoked by the first TBS of Schaffer collaterals at $1.5 \mathrm{~mm}\left(B_{1}\right), 2.0 \mathrm{~mm}\left(B_{2}\right)$, or $2.5 \mathrm{~mm}\left(B_{3}\right)$. No differences between NCAMff - and NCAMff + mice were seen. Stimulus artifacts were blanked. Calibration: $\left(B_{1}-B_{3}\right) 200 \mathrm{msec}$ and $0.5 \mathrm{mV}$. C, Input- output curves for slopes of fEPSPs evoked by stimulation of $S$ chaffer collaterals at different stimulation strengths at 1.5, 2.0, and $2.5 \mathrm{~mm}$ extracellular $\mathrm{Ca}^{2+}$ concentrations. Significant differences between NCAMff - and NCAMff + mice were observed at $1.5 \mathrm{~mm} \mathrm{Ca}{ }^{2+} . D, E$, Cumulative plots showing levels of paired-pulse facilitation $(D)$ and STP and LTP $(E)$ as a function of extracellular $\mathrm{Ca}^{2+}$ concentration. STP was measured as the maximal potentiation above 100\% during 0-1 min after TBS, and LTP was measured as the mean potentiation 50 - 60 min after TBS. Significant differences between NCAMff - and NCAMff + mice were found for PPF at $1.5 \mathrm{~mm}$ and for LTP at 1.5 and 2.0 mm extracellular $\mathrm{Ca}^{2+}$ concentrations. ${ }^{*} p<0.05$ ( $t$ test); statistically significant differences between NCAMff - and NCAMff + mice.

0.01) (Fig. 5E). There was no significant difference in fEPSPs elicited by TBS (Fig. $5 B_{3}$ ) and STP between genotypes at $2.5 \mathrm{mM} \mathrm{Ca}^{2+}$ $(66.5 \pm 5.2 \%$ in NCAMff - and $57.8 \pm 5.2 \%$ in NCAMff + mice; $p>0.2$ ). Strikingly, the levels of LTP in NCAMff + mutants ( $37.0 \pm$ $3.2 \%$ ) were increased to levels seen in NCAMff - mice $(31.5 \pm 5.0 \%$; $p>0.3)$ (Fig. $5 A_{3}$ ).

Considering all data for the three extracellular $\mathrm{Ca}^{2+}$ concentrations that were tested, significant effects of both genotype and $\mathrm{Ca}^{2+}$ concentration on LTP (genotype, $F_{(1,66)}=13.19, p=0.001$; $\mathrm{Ca}^{2+}$ concentration, $F_{(2,66)}=4.16, p<0.05$ ) and STP (genotype, $F_{(1,66)}=4.57, p<0.05 ; \mathrm{Ca}^{2+}$ concentration, $F_{(2,66)}=14.89, p<$ $0.001)$ were revealed by the two-way ANOVA. Thus, there are robust differences in LTP at 1.5 and $2.0 \mathrm{mM} \mathrm{Ca}^{2+}$ concentrations between genotypes but not at a $\mathrm{Ca}^{2+}$ concentration of $2.5 \mathrm{mM}$ (Fig. 5E).
Input-output (stimulus-response) curves and paired-pulse facilitation for fEPSPs evoked by stimulation of Schaffer collaterals with a $50 \mathrm{msec}$ interval were not different between NCAMff + mutants and their NCAMff - littermates at 2.0 and 2.5 $\mathrm{mM} \mathrm{Ca}{ }^{2+}$ concentrations (Fig. 5C,D). However, lowering the $\mathrm{Ca}^{2+}$ concentration to $1.5 \mathrm{~mm}$ revealed a difference between genotypes; NCAMff + mice showed elevated levels of basal excitatory transmission (Fig. $5 \mathrm{C}$ ) and decreased pairedpulse facilitation $(1.98 \pm 0.08$ in NCAMff - vs $1.72 \pm 0.04$ in NCAMff + mice; $p<0.05$ ) (Fig. 5D). The two-way ANOVA also showed significant effects of $\mathrm{Ca}^{2+}$ concentration $\left(F_{(2,40)}=59.9 ; p<\right.$ $0.001)$ and genotype $\times \mathrm{Ca}^{2+}$ concentration $\left(F_{(2,40)}=4.12 ; p<0.05\right)$ on pairedpulse facilitation.

Because hippocampal slices deficient in polysialic acid (a carbohydrate associated with NCAM) show impairment of longterm depression in the $\mathrm{CA} 1$ region (Muller et al., 1996; Eckhardt et al., 2000), we also examined NCAMff + mice in this form of synaptic plasticity. Two spaced trains of low-frequency stimulation induced a persistent significant decrease in NCAMffmice by $28.6 \pm 6.1 \%$ at $1.5 \mathrm{mM} \mathrm{Ca}^{2+}$ and $18.7 \pm 4.3 \%$ at $2.0 \mathrm{mM} \mathrm{Ca}^{2+} 50-60 \mathrm{~min}$ after low-frequency stimulation (Fig. $\left.6 A_{1}, A_{2}, B\right)$. In contrast, no LTD was induced in NCAMff + mice $(3.6 \pm 5.1 \%$ at $1.5 \mathrm{mM} \mathrm{Ca}^{2+}$ and $1.5 \pm 4.3 \%$ at $2.0 \mathrm{~mm}$ $\mathrm{Ca}^{2+} ; p<0.05$ vs NCAMff- mice). At 2.5 $\mathrm{mM} \mathrm{Ca}^{2+}$, there was no significant difference between genotypes in the levels of depression $(8.2 \pm 4.3 \%$ in NCAMff- vs $8.9 \pm 4.6 \%$ in NCAMff + mice; $p>0.9)$ (Fig. $6 A_{3}$ ). The two-way ANOVA also showed significant effects of genotype $\left(F_{(1,35)}=11.94 ; p=0.001\right)$ and genotype $\times \mathrm{Ca}^{2+}$ concentration $\left(F_{(2,35)}=3.67 ; p<\right.$ $0.05)$ on LTD but significant influence of neither genotype nor $\mathrm{Ca}^{2+}$ concentration on the levels of short-term depression (Fig. $6 B$ ). Thus, our data show that NCAM is required for LTD at 1.5 and $2.0 \mathrm{~mm}$ concentrations of $\mathrm{Ca}^{2+}$.

NCAM - / - mice also showed impaired synaptic plasticity in the CA3 region (Cremer et al., 1998). LTP at mossy fiber synapses in the CA3 region has features distinct from CA1 LTP, being independent of postsynaptic NMDA receptors, mediated by cyclic adenosine monophosphate, and activated by adenylate cyclase and protein kinase A (Weisskopf et al., 1994). To select mossy fiber fEPSPs and avoid responses mixed with associational-commissural fEPSPs (Claiborne et al., 1993), multiple criteria were used (see Materials and Methods), which were similar to those in the study on NCAM-/- mice (Cremer et al., 1998) and in several recent studies performed in our laboratory and others (Eckhardt et al., 2000; Chen et al., 2001; Contractor et al., 2001; Evers et al., 2002; Calixto et al., 2003).

A train of 40 stimuli applied at $0.33 \mathrm{~Hz}$ induced a frequency 

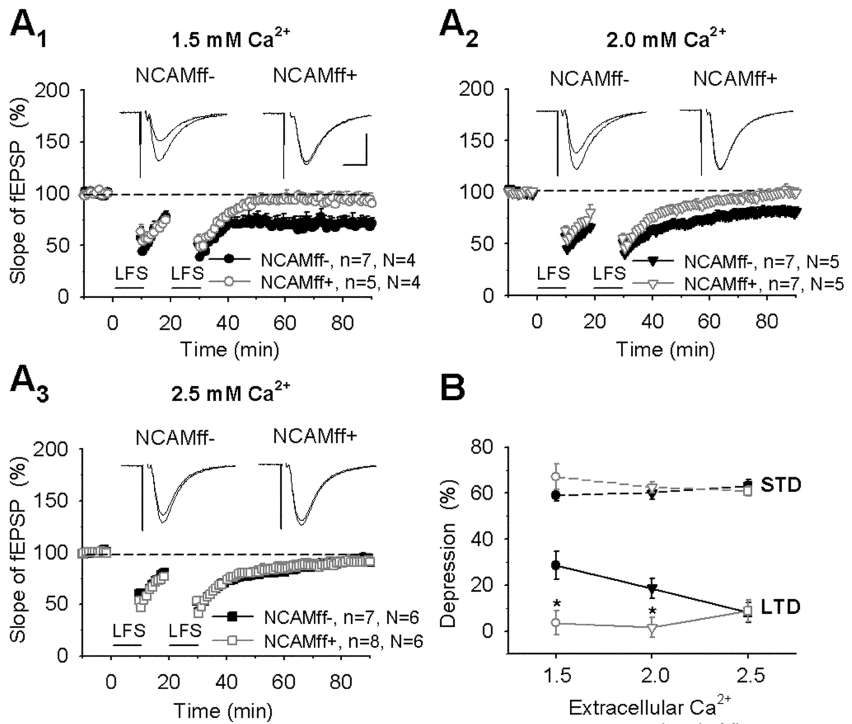

B

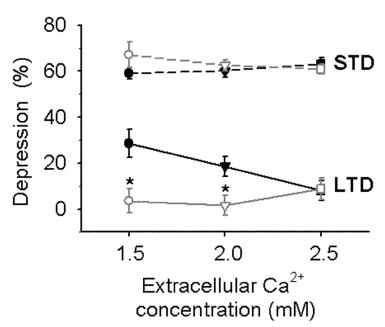

Figure 6. Impairment of LTD in NCAMff + mice at 1.5 and $2.0 \mathrm{~mm}$ extracellular $\mathrm{Ca}^{2+}$ concentrations. $A_{1}-A_{2}$, Two trains of low-frequency stimulation (LFS) of Schaffer collaterals at 1.5 $\mathrm{mm}\left(A_{1}\right)$ and $2.0 \mathrm{~mm}\left(A_{2}\right)$ extracellular $\mathrm{Ca}^{2+}$ concentrations induced a persistent decrease in slopes of fEPSPs in the CA1 region of slices from NCAMff- mice. $A_{3}, \mathrm{At} 2.5 \mathrm{~mm} \mathrm{Ca}^{2+}$, the same stimulation resulted in transient depression. In slices from NCAMff+ mice, no persistent depression was induced at the extracellular $\mathrm{Ca}^{2+}$ concentrations tested. The mean slope of fEPSPs recorded $0-10$ min before LFS was taken as 100\%. Horizontal bars indicate delivery of LFS. In all panels, data represent mean \pm SEM, $n$ provides the number of tested slices, and $N$ provides the number of tested mice. Insets show averages of $30 \mathrm{fEPSPs}$ recorded $10 \mathrm{~min}$ before and $50-60$ min after LFS. Calibration: $\left(A_{1}-A_{3}\right) 10 \mathrm{msec}$ and $0.5 \mathrm{mV}$. B, Cumulative plots showing levels of STD and LTD as a function of extracellular $\mathrm{Ca}^{2+}$ concentration. STD was measured as the maximal decrease from $100 \%$ during $0-1$ min after LFS, and LTD was measured as the mean depression $50-60$ min after LFS. ${ }^{*} p<0.05$ ( $t$ test); statistically significant differences between NCAMff - and NCAMff + mice were found for LTD at 1.5 and $2.0 \mathrm{~mm}$ extracellular $\mathrm{Ca}^{2+}$ concentrations.

facilitation to $260.2 \pm 7.4 \%$ in NCAMff - and to a significantly higher level of $308.0 \pm 11.6 \%$ in NCAMff + mice $(p<0.01$; Fig. $7 A)$. However, there was no difference between genotypes in terms of paired-pulse facilitation with a $50 \mathrm{msec}$ interpulse interval $(1.73 \pm 0.06$ in NCAMff - and $1.86 \pm 0.05$ in NCAMff + mice; $p>0.1)$. L-CCG1 diminished the amplitude of fEPSPs in both genotypes to a similar extent (Fig. $7 B$ ). To record mossy fiber LTP and avoid an increase in synaptic efficacy that could originate from contaminating associational-commissural input, we induced potentiation in the presence of AP-5 and thus blocked NMDA receptor-dependent synaptic plasticity in associational-commissural input (Harris and Cotman, 1986; Ito et al., 1997) while leaving NMDA receptor-independent mossy fiber LTP untouched. The NMDA receptor antagonist AP-5 did not affect the amplitude of fEPSPs in neither NCAMff- nor NCAMff + mice (Fig. 7C,D). HFS performed in the presence of AP-5 induced a strong increase in fEPSP amplitudes (Fig. 7C,D), resembling reported profiles of CA3 LTP in mice (Eckhardt et al., 2000; Contractor et al., 2001; Evers et al., 2002; Dietrich et al., 2003). Post-tetanic potentiation (PTP) during the first $1 \mathrm{~min}$ after HFS was $\sim 900 \%$ above the baseline in both genotypes, and mean potentiation measured 50-60 min after induction of LTP was $62.8 \pm 17.8 \%$ in NCAMff - and $74.8 \pm 19.1 \%$ in NCAMff + mice $(p>0.6)$ (Fig. $7 C)$. These recordings were performed under the same conditions as in the previous study (Cremer et al., 1998). In addition, we attenuated the induction protocol, trying to reveal differences in the thresholds for induction of LTP be-
A
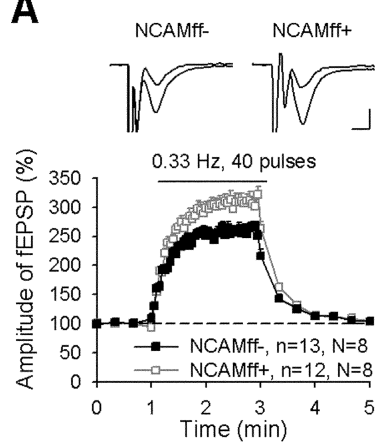

B
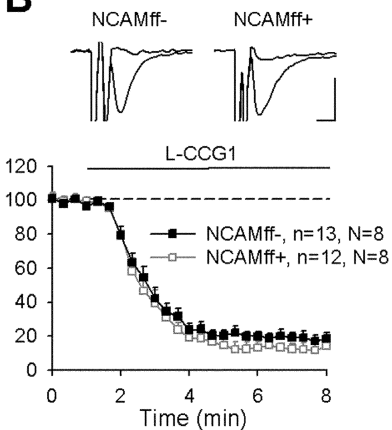

C
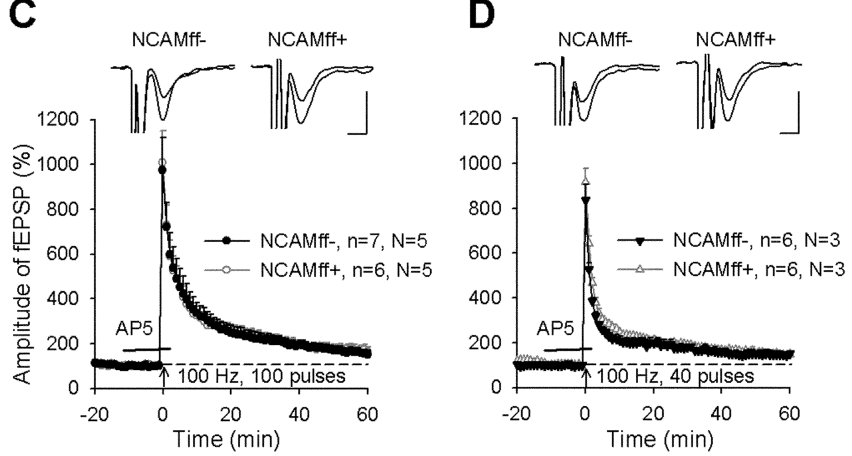

Figure 7. Normal LTP in the CA3 region of NCAMff + mice. $A$, Stimulation of mossy fibers with a frequency of $0.33 \mathrm{~Hz}$ increases the amplitudes of fEPSPs more strongly in slices from $\mathrm{NCAMff}+$ than in slices from NCAMff - mice. Data here and below represent mean $\pm \mathrm{SEM}, n$ is the number of tested slices, and $N$ is the number of tested mice. Insets show averages of 15 fEPSPs recorded before and during frequency facilitation. Calibration: $5 \mathrm{msec}$ and $50 \mu \mathrm{V}$. B, Application of the type II metabotropic glutamate receptor agonist L-CCG1 (10 $\mu \mathrm{m})$ reduces the amplitude of fEPSPs in slices from both NCAMff + and NCAMff - mice to the same level. Insets show averages of 15 fEPSPs recorded before and 5 min after application of L-CCG1. C, D, HFS of mossy fibers with $100(C)$ or $40(D)$ pulses (applied at time point 0 ) evokes a similar increase in the slopes of fEPSPs in slices from NCAMff + and NCAMff - mice. The time interval of the application of the NMDA receptor antagonist AP-5 is shown by a horizontal bar. Mean slope of fEPSPs recorded $0-10$ min before HFS was taken as $100 \%$. Insets show averages of $30 \mathrm{fEPSPS}$ recorded 10 min before and 50-60 min after induction of LTP in NCAMff + and NCAMffmice.

tween the two genotypes. HFS consisting of 40 instead of 100 pulses resulted in reduced PTP and LTP levels in both genotypes. However, again, no significant difference could be observed between NCAMff - and NCAMff + mice $(p>0.9)$ (Fig. $7 D)$. Thus, we conclude that NMDA receptor-independent LTP in mossy fiber-CA3 synapses is not impaired in NCAMff + mutants under conditions when a deficit has been observed in constitutively NCAM-deficient mice.

\section{Behavioral analysis in the water maze}

The protocol of the current study was modified, compared with that used for testing of NCAM-/- mice (Cremer et al., 1994; Stork et al., 2000), to minimize stress and enable all animals to acquire the task. As a result, none of the animals showed thigmotaxis or floating during training and probe trials, reflecting behavioral coping strategies that could confound the analysis of spatial learning as well as short- and long-term spatial memory. NCAMff + and NCAMff - mice both learned to navigate to the platform over the course of the first 5 training days, as indicated by the decrease in escape latencies (Fig. 8A) and the length of swim path (data not shown). No significant difference between the two genotypes was found in these two parameters [escape latency: genotype, $F_{(1,26)}=0.73, p>0.3$; day, $F_{(4,104)}=34.2, p<$ 
A

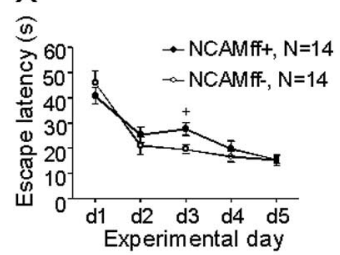

C
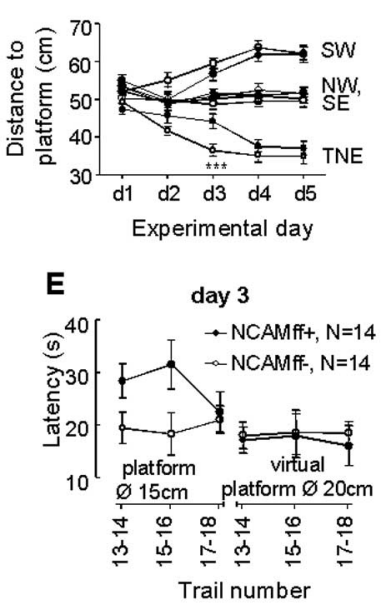
(pairs)
B

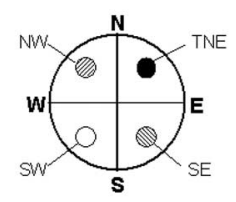

D
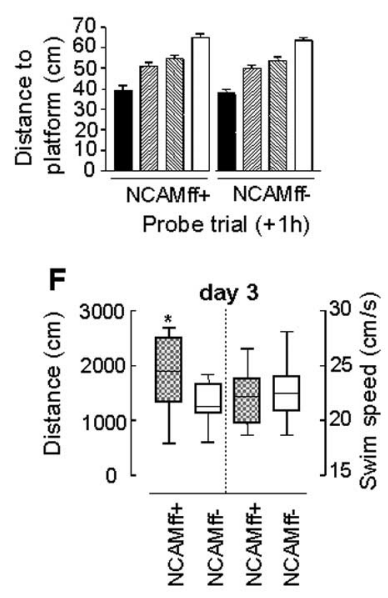

Figure 8. Spatial learning and memory of NCAMff + and NCAMff - mice in the water maze. $A, \mathrm{NCAM}+$ and NCAMff - mice show a similar decrease in escape latencies over the course of the five training days, except for day 3 when the diameter of the platform was reduced. $B$, The water maze is virtually divided into four quadrants (NE, NW, SE, SW). The target platform is positioned in the NE quadrant (TNE). Three additional virtual platforms are defined in the other quadrants as a means for studying spatial search strategies. C, Mean distance to TNE and the three other virtual platform positions over the course of the five training days of NCAMffcontrols (open circles) and NCAMff + mutants (filled circles). A reduction in the mean distance to the platform is considered to reveal selective searching. $D$, Mean distance to TNE and the three other virtual platform positions during the probe trial at day 5 ( $1 \mathrm{hr}$ after training). The pattern of the bars corresponds to the pattern of the platforms depicted in $B$. E, Detailed analysis of the behavioral responses of NCAMff + and NCAMff - mice to the reduction of the platform size at day 3. NCAMff + mice showed prolonged escape latencies when the platform diameter was reduced to $15 \mathrm{~cm}$. In contrast, NCAMff + mice would have found the platform of the original size as fast as NCAMff - mice. Data of two consecutive trials were averaged as indicated in the abscissa. F, NCAMff + mice swam a longer distance before they reached the platform on day 3. In contrast, the mean swim speed was similar to NCAMff - controls. All values are expressed as mean \pm SEM, and $N$ is the number of tested mice. $+p<0.05$ ( $t$ test and $U$ test); *** $p<0.001$ TNE-NCAMff - versus TNE-NCAMff + mice (ANOVA followed by Fisher's LSD). Box plots, ${ }^{*} p<0.05$ (Mann-Whitney U test).

0.0001 ; genotype $\times$ day, $F_{(4,104)}=1.71, p>0.1$; two-way ANOVA (genotype, day) for repeated measurements (day)]. However, NCAMff - mice reached the platform faster than the NCAMff + mutants at day 3 , when the size of the platform was reduced from 20 to $15 \mathrm{~cm}$ (19.6 vs $27.5 \mathrm{sec} ; p<0.05$; unpaired $t$ test and Mann-Whitney $U$ test). Interestingly, NCAMff - and NCAMff + mice would have reached the platform with the same latencies if the former dimension of the platform $(20 \mathrm{~cm})$ had been considered ( 18.4 vs $17.1 \mathrm{sec} ; p>0.05$ ). More detailed analysis of escape latencies shown during the six training trials at day 3 revealed that NCAMff + mutants differed from NCAMffmice in their escape latencies only during the first four trials and finally reached the same level of performance as NCAMff- littermate controls (Fig. $8 E$ ) (genotype, $F_{(1,26)}=6.70 ; p<0.05$ ). In contrast, escape latencies to the former $20 \mathrm{~cm}$ platform would have been similar for the two genotypes throughout the six training trials (Fig. 8E) (statistics not shown). At day 3, NCAMff+

mice showed not only increased escape latencies but also an increased length of the swim path and a similar swim speed (Fig. $8 F)$. Together, these data indicate that NCAMff + mice searched less precisely for the platform than NCAMff- controls, leading to the prolonged escape latencies.

Analysis of the data speaks against altered emotional behavior of NCAMff + mice, particularly on training day 3, when differences in learning were revealed. In case of unspecific "emotional disturbances," one would expect the mutants to either search (slowly) the place where the (larger) platform had been or show increased floating. Yet, NCAMff + mice showed the same swim speed as NCAMff - mice and an increased swim path length. Importantly, NCAMff + mice would have reached the original platform as fast as their littermate controls but showed a significantly increased escape latency for the smaller platform. Because all animals reached the platform during each of the training trials on day 3 , the mutants also recognized that there was a platform still localized at the original platform position. Consequently, if the increased escape latency on day 3 was attributable to different emotional responses of NCAMff + mice to the changed platform size, mutants should have reached the same level of performance as their NCAMff - littermate controls already after the initial trial, which they did not.

To specify the search strategies during learning, we analyzed the animals' mean distance to the platform and to three other virtual platform positions (Fig. $8 B$ ). As shown in Figure $8 C$, all mice searched closer to the platform than other virtual positions over the course of training (day, $F_{(4,130)}=4.73, p=0.001$; platform, $F_{(3,390)}=159.9, p<0.0001$; day $\times$ platform, $F_{(12,390)}=$ $10.6, p<0.0001)$. A significant difference between NCAMffand NCAMff + mice in the "distance to the target platform in the NE quadrant" (TNE) [genotype $\times$ platform, $F_{(3,390)}=3.06, p<$ 0.05; three-way ANOVA (genotype, day, platform) for repeated measurements (platform)] was observed at training day $3(p<$ 0.001; Fisher's LSD). If the genotypes were analyzed separately, both NCAMff + (platform, $F_{(3,195)}=64.7, p<0.0001$; day $\times$ platform, $\left.F_{(12,195)}=5.40, p<0.0001\right)$ and NCAMff - mice (platform, $F_{(3,195)}=96.3, p<0.0001$; day $\times$ platform, $F_{(12,195)}=6.23$, $p<0.0001)$ searched closer to the target platform than the other virtual platform positions. However, whereas NCAMff- mice showed a spatial preference for the target platform as early as day $2(\mathrm{TNE}<\mathrm{SE}=\mathrm{NW}<\mathrm{SW})($ Fig. $8 B, C)$, NCAMff + mice showed a selective search strategy only from day 3 onward.

NCAMff + mice reached the same level of behavioral performance as their NCAMff- littermate controls at the end of the training period. This allowed us to study the role of NCAM in formation of short- and long-term spatial memory by performing two probe trials both 1 and $64 \mathrm{hr}$ after the last training trial. There were no significant genotype differences in the relative time spent or the relative length of swim path in the target quadrant (data not shown). Immediately after training (1 hr), mice searched closer to the former platform position than the other virtual positions (platform, $F_{(3,78)}=57.3 ; p<0.0001$ ) (Fig. $8 D$ ) with no significant difference between genotypes (genotype, $F_{(1,26)}=1.37, p>0.2$; genotype $\times$ platform, $F_{(3,78)}=0.002, p>$ $0.9)$. Similarly, no significant difference could be detected between the two genotypes in their selectivity for the former target quadrant $64 \mathrm{hr}$ after the last training trial (data not shown). As indicated by the number of visits of the former platform position, NCAMff + mice searched similarly, precisely as NCAMff- mice, during the $1 \mathrm{hr}$ probe and $64 \mathrm{hr}$ trials (statistics not shown). Altogether, the behavioral data indicate that NCAMff + mice are deficient in the acquisition of precise spatial orientation at the 
Table 1. Synaptic transmission and plasticity in NCAMff + mice

\begin{tabular}{llll}
\hline & $\begin{array}{l}\text { Extracellular } \mathrm{Ca}^{2+} \\
\text { concentration }\end{array}$ & & \\
\cline { 2 - 3 } Parameters & $1.5 \mathrm{~mm}$ & $2.0 \mathrm{~mm}$ & $2.5 \mathrm{~mm}$ \\
\hline CA1 & & & \\
$\quad$ Basal synaptic transmission & $\uparrow$ & $=$ & $=$ \\
Paired-pulse facilitation & $\downarrow$ & $=$ & $=$ \\
Short-term potentiation & $=$ & $\downarrow$ & $=$ \\
Long-term potentiation & $\downarrow$ & $=$ & $=$ \\
Short-term depression & $=$ & $\downarrow$ & $=$ \\
Long-term depression & $\downarrow$ & & $=$ \\
CA3 & - & - & $=$ \\
Paired-pulse facilitation & - & - & $=$ \\
Frequency facilitation & - & - & $=$ \\
Post-tetanic potentiation & - & - & $=$ \\
Long-term potentiation & & & \\
\hline
\end{tabular}

$=$, No difference between NCAMff + and NCAMff - mice; $\uparrow$, increase in NCAMff + mice; $\downarrow$, decrease in NCAMff + mice; - , not studied.

beginning of the learning period that could be overcome by training. However, they are not impaired in short-term and long-term spatial memory compared with their NCAMff- littermate controls.

\section{Discussion}

We generated a mouse in which the NCAM gene is inactivated after cessation of the major developmental events by using a bipartite cre-lox recombination system under control of the $\alpha$ CaMKII promoter. Depending on the integration site of the $\alpha$ CaMKII-cre transgene and the local conformation of the floxed allele, the pattern and efficiency of cre-mediated disruption of the target gene may vary (Tsien et al., 1996). In the case of NCAMff+ mutants, we observed an ablation of NCAM in the hippocampus from P22 onward. No further reduction of NCAM expression in the hippocampus was observed beyond P49. Quantitative Western blot analysis indicated that the amount of residual NCAM protein in the hippocampus of NCAMff + mutants is $\sim 10 \%$ of that present in NCAMff- control littermates. The observations that the $\alpha$ CamKII promoter drives heterologous gene expression in a neuron- and age-specific manner (Mayford et al., 1995; Mantamadiotis et al., 2002) and that NCAM is expressed in both neurons (Persohn et al., 1989; Prieto et al., 1989) and astrocytes (Keilhauer et al., 1985; Noble et al., 1985), the residual NCAM immunoreactivity in the NCAMff + hippocampus is likely to be contributed by astrocytes, immature neurons, and striatal and cortical axonal projections.

The NCAMff + mutants are normal in their general development and overall body weight and fertility. Contrary to NCAM - / - mice, neither reduction in the size of brain and olfactory bulb nor abnormalities in the cytoarchitecture of the hippocampus, such as dispersed and bilayered appearance of the pyramidal cell layer, were observed. Interestingly, the hippocampal mossy fiber projections appear intact in the NCAMff + mutant, indicating that NCAM may be dispensable for the continued process of neurogenesis in the dentate gyrus and formation and maintenance of mossy fiber projections in the adult hippocampus.

Electrophysiological analysis of NCAMff + mutants revealed a number of abnormalities (Table 1), particularly impairment in the NMDA receptor-dependent form of LTP and LTD in the CA1 region at 1.5 and $2.0 \mathrm{~mm}$ extracellular $\mathrm{Ca}^{2+}$. Because in conditional NCAM mutants the reduced LTP in the CA1 region could be rescued by elevation of the extracellular $\mathrm{Ca}^{2+}$ concentration, we think that NCAM plays an acute role in the induction of LTP (Staubli et al., 1998), specifically by regulation of $\mathrm{Ca}^{2+}$ - dependent signaling. An increase in intracellular $\mathrm{Ca}^{2+}$ concentration triggered by NCAM antibodies (Schuch et al., 1989), which work agonistically for NCAM-triggered signaling, is consistent with a reduction in $\mathrm{Ca}^{2+}$ signaling after genetic ablation of NCAM. LTP levels have been reported in wild-type rodents to be similar at $\mathrm{Ca}^{2+}$ concentrations in the range of 1.5 to $2.5 \mathrm{~mm}$ but steeply decrease at $\sim 1 \mathrm{~mm}$ (Dunwiddie and Lynch, 1979; Mulkeen et al., 1988; Stringer and Lothman, 1988). In NCAMff+ mutants, normal LTP can be induced at $2.5 \mathrm{~mm}$ but not at the lower concentrations tested, thus indicating a reduction in responsiveness to extracellular $\mathrm{Ca}^{2+}$ concentration to induce LTP under NCAM deficiency by a factor of $\sim 2.5$. With this reduction, LTP would be impaired at $2 \mathrm{mM} \mathrm{Ca}^{2+}$ and below and normal at $2.5 \mathrm{mM}$, as we indeed found in NCAMff + mice. The reasons for such reduction would be a decrease in NMDA receptor- and voltage-dependent $\mathrm{Ca}^{2+}$ channel-mediated $\mathrm{Ca}^{2+}$ influx or attenuated activities of intracellular $\mathrm{Ca}^{2+}$-dependent protein kinases involved in LTP. Currently, the most plausible hypothesis is that NCAM mediates accumulation of NMDA receptors, PKC, and other components of the postsynaptic machinery via the cytoskeletal linker protein spectrin. This hypothesis is supported by: (1) biochemical data showing an interaction between spectrin and NMDA receptors, PKC, and several other postsynaptic proteins (Wechsler and Teichberg, 1998); (2) biochemical and functional data showing the importance of interaction between NCAM and spectrin (Pollerberg et al., 1986; Sytnyk et al., 2002; Leshchyns'ka et al., 2003); (3) postembedding immunoelectron microscopic data showing coredistribution of NR2A and NCAM180 after induction of LTP in the dentate gyrus (Fux et al., 2003). We speculate that the NCAM-spectrin complex may regulate coupling of activities of NMDA receptors and $\mathrm{Ca}^{2+}$ dependent kinases by bringing together these components of the postsynaptic machinery in distinct microdomains within postsynaptic sites. These complexes may also include receptors for FGF, GDNF, and BDNF, which are known to interact with NCAM (Saffell et al., 1997; Muller et al., 2000; Paratcha et al., 2003).

The NMDA receptor-independent form of LTP in the CA3 region was found to be normal in conditional NCAM mutants, suggesting that the previously found impairment of CA3 LTP in NCAM-/- mice (Cremer et al., 1998) is possibly related to the abnormal development of mossy fiber projections in these animals. No differences between NCAMff + and NCAMff - mice were detected in two other forms of short-term plasticity in CA3, namely paired-pulse facilitation and post-tetanic potentiation. Interestingly, however, NCAMff + mutants showed slightly but significantly increased frequency facilitation in CA3 compared with NCAMff - mice, suggesting that the function of NCAM is not limited to modulation of NMDA receptor-dependent plasticity in CA1. Because at $1.5 \mathrm{mM} \mathrm{Ca}^{2+}$, NCAMff + mice showed decreased paired-pulse facilitation in Schaffer collateral-CA1 synapses, NCAM ablation appears to have opposite effects on two forms of short-term plasticity at two different types of synapses in the hippocampus. No differences in frequency facilitation were seen between NCAM-I- and wild-type mice (Cremer et al., 1998; O.B. and A.D., unpublished data), indicating that conditional NCAM deficiency leads to an abnormality that is compensated for in NCAM $-/-$ mice.

Additionally, NCAMff + mice show an increase in basal excitatory synaptic transmission in the CA1 region at $1.5 \mathrm{mM} \mathrm{Ca}^{2+}$, accompanied by a decrease in paired-pulse facilitation, suggesting that probability of release in Schaffer collaterals is increased in NCAMff + mice compared with NCAMff- mice. Lowering 
$\mathrm{Ca}^{2+}$ has been reported to uncover differences between genotypes. Schoch et al. (2002) detected larger differences in pairedpulse modulation of IPSCs between RIM $1 \alpha$ knock-out and wildtype mice at $1 \mathrm{mM} \mathrm{Ca}^{2+}$ than at $3 \mathrm{mM} \mathrm{Ca}^{2+}$. It will be important to investigate whether these abnormalities in NCAMff + mice reflect alterations in presynaptic organization of Schaffer collateral terminals, as observed at the neuromuscular junction of NCAM - / - mice (Polo-Parada et al., 2001). Presynaptic defects could be a potential reason for impaired LTP in NCAMff + mice, for instance, if less transmitter is released during theta-burst stimulation. However, the difference between NCAMff + and NCAMffmice in paired-pulse facilitation was observed at $1.5 \mathrm{mM} \mathrm{Ca}^{2+}$ but not at $2.0 \mathrm{mM} \mathrm{Ca}^{2+}$, whereas the differences in LTP between genotypes were seen at both concentrations, suggesting that it is unlikely that abnormalities in paired-pulse facilitation and LTP are related. Also, fEPSPs evoked by theta-burst stimulation and the magnitude of short-term potentiation appeared normal in NCAMff- mice, supporting the view that the presynaptic pattern of activity during induction of LTP is normal in NCAMff + mice.

Conditional ablation of NCAM in $\alpha$ CaMKII-expressing cells had no effect on the general ability of the NCAMff + mice to acquire the water maze task, navigate along global landmarks, and form short- and long-term spatial memory. This manifested itself in an unaltered spatial preference for the target position in the probe trials performed 1 and $64 \mathrm{hr}$ after the last training trial compared with their NCAMff- littermate controls.

However, in the first trials, NCAMff + mice were less precise in spatial searching, because they found the platform more slowly on training day 3 when the size of the platform was reduced from 20 to $15 \mathrm{~cm}$. Furthermore, NCAMff + mice were slightly retarded in the development of selective spatial navigation over the course of the training days. With ongoing training, these differences disappeared. The more severe deficits in spatial learning and memory observed in constitutive NCAM $-/-$ mice (Cremer et al., 1994; Stork et al., 2000) are thus likely related to developmental defects and the altered emotional behavior of these animals (Stork et al., 1997) that lead, for instance, to the development of passive coping strategies such as floating. It is tempting to speculate that these deficits of NCAM $-/-$ mice are related to abnormal mossy fiber lamination and CA3 LTP or could be overcome by using the low-stress protocol used in the present study.

The question remains as to how our observations on altered spatial learning in NCAMff + mice relate to the impaired synaptic plasticity in acute slices of NCAMff + mice. The fact that NCAMff + mice show a slower rate in targeting the smaller platform at training day 3 compared with NCAMff - mice could reflect the reduced levels of CA1 LTP and LTD. Both of these forms of synaptic plasticity may be involved because synaptic connections in the neural circuitry of learned animals could undergo modifications of different polarity, thus synergizing with respect to information storage capacity. A recent publication indicates that CA1 LTP is required for flexible, working memory components but not for reference memory components in spatial learning tasks (Reisel et al., 2002). Accordingly, in our study, altered LTP would correspond to the retarded acquisition of a precise search strategy but not to escape latencies and preference to the target position as indicators of intact reference memory. Although impairments in synaptic plasticity appear generally less extensive in conditional versus constitutive NCAM-deficient mice, our study shows that NCAM plays an important role in regulation of synaptic functions in the hippocampal CA1 region and contributes to spatial learning.

\section{References}

Arami S, Jucker M, Schachner M, Welzl H (1996) The effect of continuous intraventricular infusion of L1 and NCAM antibodies on spatial learning in rats. Behav Brain Res 81:81-87.

Becker CG, Artola A, Gerardy-Schahn R, Becker T, Welzl H, Schachner M (1996) The polysialic acid modification of the neural cell adhesion molecule is involved in spatial learning and hippocampal long-term potentiation. J Neurosci Res 45:143-152.

Benson DL, Schnapp LM, Shapiro L, Huntley GW (2000) Making memories stick: cell-adhesion molecules in synaptic plasticity. Trends Cell Biol 10:473-482.

Bixby JL, Pratt RS, Lilien J, Reichardt LF (1987) Neurite outgrowth on muscle cell surfaces involves extracellular matrix receptors as well as $\mathrm{Ca}^{2+}$. dependent and -independent cell adhesion molecules. Proc Natl Acad Sci USA 84:2555-2559.

Bronner-Fraser M, Wolf JJ, Murray BA (1992) Effects of antibodies against $\mathrm{N}$-cadherin and N-CAM on the cranial neural crest and neural tube. Dev Biol 153:291-301.

Buchholz F, Angrand PO, Stewart AF (1998) Improved properties of FLP recombinase evolved by cycling mutagenesis. Nat Biotechnol 16:657-662.

Buskirk DR, Thiery JP, Rutishauser U, Edelman GM (1980) Antibodies to a neural cell adhesion molecule disrupt histogenesis in cultured chick retinae. Nature 285:488-489.

Calixto E, Thiels E, Klann E, Barrionuevo G (2003) Early maintenance of hippocampal mossy fiber-long-term potentiation depends on protein and RNA synthesis and presynaptic granule cell integrity. J Neurosci 23:4842-4849.

Chen YL, Huang CC, Hsu KS (2001) Time-dependent reversal of long-term potentiation by low-frequency stimulation at the hippocampal mossy fiber-CA3 synapses. J Neurosci 21:3705-3714.

Claiborne BJ, Xiang Z, Brown TH (1993) Hippocampal circuitry complicates analysis of long-term potentiation in mossy fiber synapses. Hippocampus 3:115-121.

Contractor A, Swanson G, Heinemann SF (2001) Kainate receptors are involved in short- and long-term plasticity at mossy fiber synapses in the hippocampus. Neuron 29:209-216.

Cremer H, Lange R, Christoph A, Plomann M, Vopper G, Roes J, Brown R, Baldwin S, Kraemer P, Scheff S (1994) Inactivation of the N-CAM gene in mice results in size reduction of the olfactory bulb and deficits in spatial learning. Nature 367:455-459.

Cremer H, Chazal G, Goridis C, Represa A (1997) NCAM is essential for axonal growth and fasciculation in the hippocampus. Mol Cell Neurosci 8:323-335.

Cremer H, Chazal G, Carleton A, Goridis C, Vincent JD, Lledo PM (1998) Long-term but not short-term plasticity at mossy fiber synapses is impaired in neural cell adhesion molecule-deficient mice. Proc Natl Acad Sci USA 95:13242-13247.

Cunningham BA, Hemperly JJ, Murray BA, Prediger EA, Brackenbury R, Edelman GM (1987) Neural cell adhesion molecule: structure, immunoglobulin-like domains, cell surface modulation, and alternative RNA splicing. Science 236:799-806.

Delling M, Wischmeyer E, Dityatev A, Sytnyk V, Veh RW, Karschin A, Schachner M (2002) The neural cell adhesion molecule regulates cellsurface delivery of G-protein-activated inwardly rectifying potassium channels via lipid rafts. J Neurosci 22:7154-7164.

Dietrich D, Kirschstein T, Kukley M, Pereverzev A, von der BC, Schneider T, Beck H (2003) Functional specialization of presynaptic Cav2.3 $\mathrm{Ca}^{2+}$ channels. Neuron 39:483-496.

Dityatev A, Dityateva G, Schachner M (2000) Synaptic strength as a function of post- versus presynaptic expression of the neural cell adhesion molecule NCAM. Neuron 26:207-217.

Doherty P, Cohen J, Walsh FS (1990) Neurite outgrowth in response to transfected N-CAM changes during development and is modulated by polysialic acid. Neuron 5:209-219.

Doyle E, Nolan PM, Bell R, Regan CM (1992) Intraventricular infusions of antineural cell adhesion molecules in a discrete posttraining period impair consolidation of a passive avoidance response in the rat. J Neurochem 59:1570-1573.

Dunwiddie TV, Lynch G (1979) The relationship between extracellular calcium concentrations and the induction of hippocampal long-term potentiation. Brain Res 169:103-110.

Eckhardt M, Bukalo O, Chazal G, Wang L, Goridis C, Schachner M, Gerardy- 
Schahn R, Cremer H, Dityatev A (2000) Mice deficient in the polysialyltransferase ST8SiaIV/PST-1 allow discrimination of the roles of neural cell adhesion molecule protein and polysialic acid in neural development and synaptic plasticity. J Neurosci 20:5234-5244.

Evers MR, Salmen B, Bukalo O, Rollenhagen A, Bosl MR, Morellini F, Bartsch U, Dityatev A, Schachner M (2002) Impairment of L-type $\mathrm{Ca}^{2+}$ channel-dependent forms of hippocampal synaptic plasticity in mice deficient in the extracellular matrix glycoprotein tenascin-C. J Neurosci 22:7177-9714.

Fischer G, Kunemund V, Schachner M (1986) Neurite outgrowth patterns in cerebellar microexplant cultures are affected by antibodies to the cell surface glycoprotein L1. J Neurosci 6:605-612.

Fux CM, Krug M, Dityatev A, Schuster T, Schachner M (2003) NCAM180 and glutamate receptor subunits in potentiated spine synapses: an immunogold electron microscopic study. Mol Cell Neurosci 24:931-942.

Gerlai RT, McNamara A, Williams S, Phillips HS (2002) Hippocampal dysfunction and behavioral deficit in the water maze in mice: an unresolved issue? Brain Res Bull 57:3-9.

Gu H, Marth JD, Orban PC, Mossmann H, Rajewsky K (1994) Deletion of a DNA polymerase beta gene segment in T cells using cell type-specific gene targeting. Science 265:103-106.

Harris EW, Cotman CW (1986) Long-term potentiation of guinea pig mossy fiber responses is not blocked by $N$-methyl-D-aspartate antagonists. Neurosci Lett 70:132-137.

Haug FM, Blackstad TW, Simonsen AH, Zimmer J (1971) Timm's sulfide silver reaction for zinc during experimental anterograde degeneration of hippocampal mossy fibers. J Comp Neurol 142:23-31.

Holst BD, Vanderklish PW, Krushel LA, Zhou W, Langdon RB, McWhirter JR, Edelman GM, Crossin KL (1998) Allosteric modulation of AMPAtype glutamate receptors increases activity of the promoter for the neural cell adhesion molecule, N-CAM. Proc Natl Acad Sci USA 95:2597-2602.

Ito I, Futai K, Katagiri H, Watanabe M, Sakimura K, Mishina M, Sugiyama H (1997) Synapse-selective impairment of NMDA receptor functions in mice lacking NMDA receptor epsilon 1 or epsilon 2 subunit. J Physiol (Lond) 500:401-408.

Jacks T, Shih TS, Schmitt EM, Bronson RT, Bernards A, Weinberg RA (1994) Tumour predisposition in mice heterozygous for a targeted mutation in Nf1. Nat Genet 7:353-361.

Keilhauer G, Faissner A, Schachner M (1985) Differential inhibition of neurone-neurone, neurone-astrocyte and astrocyte-astrocyte adhesion by L1, L2 and N-CAM antibodies. Nature 316:728-730.

Kerr DS, Abraham WC (1995) Cooperative interactions among afferents govern the induction of homosynaptic long-term depression in the hippocampus. Proc Natl Acad Sci USA 92:11637-11641.

Landmesser L, Dahm L, Schultz K, Rutishauser U (1988) Distinct roles for adhesion molecules during innervation of embryonic chick muscle. Dev Biol 103:645-670.

Leshchyns'ka I, Sytnyk V, Morrow JS, Schachner M (2003) Neural cell adhesion molecule (NCAM) association with $\mathrm{PKC} \beta 2$ via betaI spectrin is implicated in NCAM-mediated neurite outgrowth. J Cell Biol 161:625-639.

Lindner J, Rathjen FG, Schachner M (1983) L1 mono- and polyclonal antibodies modify cell migration in early postnatal mouse cerebellum. Nature 305:427-430.

Lüthi A, Laurent JP, Figurov A, Muller D, Schachner M (1994) Hippocampal long-term potentiation and neural cell adhesion molecules L1 and NCAM. Nature 372:777-779.

Mantamadiotis T, Lemberger T, Bleckmann SC, Kern H, Kretz O, Martin Villalba A, Tronche F, Kellendonk C, Gau D, Kapfhammer J, Otto C, Schmid W, Schutz G (2002) Disruption of CREB function in brain leads to neurodegeneration. Nat Genet 31:47-54.

Manzoni OJ, Castillo PE, Nicoll RA (1995) Pharmacology of metabotropic glutamate receptors at the mossy fiber synapses of the guinea pig hippocampus. Neuropharmacology 34:965-971.

Mayford M, Wang J, Kandel ER, O’Dell TJ (1995) CaMKII regulates the frequency-response function of hippocampal synapses for the production of both LTD and LTP. Cell 81:891-904.

Minichiello L, Korte M, Wolfer D, Kuhn R, Unsicker K, Cestari V, RossiArnaud C, Lipp HP, Bonhoeffer T, Klein R (1999) Essential role for TrkB receptors in hippocampus-mediated learning. Neuron 24:401-414.

Mulkeen D, Anwyl R, Rowan M (1988) The effects of external calcium on long-term potentiation in the rat hippocampal slice. Brain Res 447:234-238.

Muller D, Wang C, Skibo G, Toni N, Cremer H, Calaora V, Rougon G, Kiss JZ (1996) PSA-NCAM is required for activity-induced synaptic plasticity. Neuron 17:413-422.

Muller D, Djebbara-Hannas Z, Jourdain P, Vutskits L, Durbec P, Rougon G, Kiss JZ (2000) Brain-derived neurotrophic factor restores long-term potentiation in polysialic acid-neural cell adhesion molecule-deficient hippocampus. Proc Natl Acad Sci USA 97:4315-4320.

Murase S, Schuman EM (1999) The role of cell adhesion molecules in synaptic plasticity and memory. Curr Opin Cell Biol 11:549-553.

Nagy A, Rossant J, Nagy R, Abramow-Newerly W, Roder J (1993) Derivation of completely cell culture-derived mice from early-passage embryonic stem cells. Proc Natl Acad Sci USA 90:8424-8428.

Niethammer P, Delling M, Sytnyk V, Dityatev A, Fukami K, Schachner M (2002) Cosignaling of NCAM via lipid rafts and the FGF receptor is required for neuritogenesis. J Cell Biol 157:521-532.

Noble M, Albrechtsen M, Moller C, Lyles J, Bock E, Goridis C, Watanabe M, Rutishauser U (1985) Glial cells express N-CAM/D2-CAM-like polypeptides in vitro. Nature 316:725-728.

Paratcha G, Ledda F, Ibanez CF (2003) The neural cell adhesion molecule NCAM is an alternative signaling receptor for GDNF family ligands. Cell 113:867-879.

Persohn E, Pollerberg GE, Schachner M (1989) Immunoelectronmicroscopic localization of the $180 \mathrm{kD}$ component of the neural cell adhesion molecule N-CAM in postsynaptic membranes. J Comp Neurol 288:92-100.

Pollerberg GE, Schachner M, Davoust J (1986) Differentiation statedependent surface mobilities of two forms of the neural cell adhesion molecule. Nature 324:462-465.

Polo-Parada L, Bose CM, Landmesser LT (2001) Alterations in transmission, vesicle dynamics, and transmitter release machinery at NCAMdeficient neuromuscular junctions. Neuron 32:815-828.

Prieto AL, Crossin KL, Cunningham BA, Edelman GM (1989) Localization of mRNA for neural cell adhesion molecule (N-CAM) polypeptides in neural and non-neural tisues by in situ hybridization. Proc Natl Acad Sci USA 86:9579-9583.

Reisel D, Bannerman DM, Schmitt WB, Deacon RM, Flint J, Borchardt T, Seeburg PH, Rawlins JN (2002) Spatial memory dissociations in mice lacking GluR1. Nat Neurosci 5:868-873.

Rutishauser U, Edelman GM (1980) Effects of fasciculation on the outgrowth of neurites from spinal ganglia in culture. J Cell Biol 87:370-378.

Saffell JL, Williams EJ, Mason IJ, Walsh FS, Doherty P (1997) Expression of a dominant negative FGF receptor inhibits axonal growth and FGF receptor phosphorylation stimulated by CAMs. Neuron 18:231-242.

Schachner M (1997) Neural recognition molecules and synaptic plasticity. Curr Opin Cell Biol 9:627-634.

Schoch S, Castillo PE, Jo T, Mukherjee K, Geppert M, Wang Y, Schmitz F, Malenka RC, Sudhof TC (2002) RIMlalpha forms a protein scaffold for regulating neurotransmitter release at the active zone. Nature 415:321-326.

Scholey AB, Rose SPR, Zamani MR, Bock E, Schachner M (1993) A role for the neural cell adhesion molecule in a late, consolidating phase of glycoprotein synthesis six hours following passive avoidance training of the young chick. Neuroscience 55:499-509.

Scholey AB, Mileusnic R, Schachner M, Rose SP (1995) A role for a chicken homologue of the neural cell adhesion molecule L1 in consolidation of memory for a passive avoidance task in the chick. Learn Mem 2:17-25.

Schuch U, Lohse MJ, Schachner M (1989) Neural cell adhesion molecules influence second messenger systems. Neuron 3:13-20.

Schuster T, Krug M, Hassan H, Schachner M (1998) Increase in proportion of hippocampal spine synapses expressing neural cell adhesion molecule NCAM180 following long-term potentiation. J Neurobiol 37:359-372.

Skibo GG, Davies HA, Rusakov DA, Stewart MG, Schachner M (1998) Increased immunogold labeling of neural cell adhesion molecule isoforms in synaptic active zones of the chick striatum 5-6 $\mathrm{h}$ after one-trial passive avoidance training. Neuroscience 82:1-5.

Staubli U, Chun D, Lynch G (1998) Time-dependent reversal of long-term potentiation by an integrin antagonist. J Neurosci 18:3460-3469.

Stork O, Welzl H, Cremer H, Schachner M (1997) Increased intermale aggression and neuroendocrine response in mice deficient for the neural cell adhesion molecule (NCAM). Eur J Neurosci 9:1117-1125. 
Stork O, Welzl H, Wotjak CT, Hoyer D, Delling M, Cremer H, Schachner M (1999) Anxiety and increased 5-HT1A receptor response in NCAM null mutant mice. J Neurobiol 40:343-355.

Stork O, Welzl H, Wolfer D, Schuster T, Mantei N, Stork S, Hoyer D, Lipp H, Obata K, Schachner M (2000) Recovery of emotional behaviour in neural cell adhesion molecule (NCAM) null mutant mice through transgenic expression of NCAM180. Eur J Neurosci 12:3291-3306.

Stringer JL, Lothman EW (1988) In vitro effects of extracellular calcium concentrations on hippocampal pyramidal cell responses. Exp Neurol 101:132-146.

Sytnyk V, Leshchyns'ka I, Delling M, Dityateva G, Dityatev A, Schachner M (2002) Neural cell adhesion molecule promotes accumulation of TGN organelles at sites of neuron-to-neuron contacts. J Cell Biol 159:649-661.

Tiunova A, Anokhin KV, Schachner M, Rose SP (1998) Three time windows for amnestic effect of antibodies to cell adhesion molecule L1 in chicks. NeuroReport 9:1645-1648.
Tomasiewicz H, Ono K, Yee D, Thompson C, Goridis C, Rutishauser U, Magnuson T (1993) Genetic deletion of a neural cell adhesion molecule variant (N-CAM-180) produces distinct defects in the central nervous system. Neuron 11:1163-1174.

Tsien JZ, Chen DF, Gerber D, Tom C, Mercer EH, Anderson DJ, Mayford M, Kandel ER, Tonegawa S (1996) Subregion- and cell type-restricted gene knockout in mouse brain. Cell 87:1317-1326.

Wechsler A, Teichberg VI (1998) Brain spectrin binding to the NMDA receptor is regulated by phosphorylation, calcium and calmodulin. EMBO J 17:3931-3939.

Weisskopf MG, Castillo PE, Zalutsky RA, Nicoll RA (1994) Mediation of hippocampal mossy fiber long-term potentiation by cyclic AMP. Science 265:1878-1882.

Wood GK, Tomasiewicz H, Rutishauser U, Magnuson T, Quirion R, Rochford J, Srivastava LK (1998) NCAM-180 knockout mice display increased lateral ventricle size and reduced prepulse inhibition of startle. NeuroReport 9:461-466. 